\title{
Functional Consequences of Synapse Remodeling Following Astrocyte-Specific Regulation of Ephrin-B1 in the Adult Hippocampus
}

\author{
Jordan Koeppen, ${ }^{1,2 *}$ (D)Amanda Q. Nguyen, ${ }^{1,3 *}$ Angeliki M. Nikolakopoulou, ${ }^{1}$ (Dichael Garcia, ${ }^{1}$ @Sandy Hanna, ${ }^{1}$ \\ Simone Woodruff, ${ }^{1}$ Zoe Figueroa, ${ }^{1}{ }^{\circledR}$ Andre Obenaus, ${ }^{4}$ and $\odot$ Iryna M. Ethell ${ }^{1,2,3}$ \\ ${ }^{1}$ Division of Biomedical Sciences, University of California Riverside School of Medicine, Riverside, California 92521, ${ }^{2}$ Cell, Molecular, and Developmental \\ Biology Graduate program, University of California Riverside, California, 92521, ${ }^{3}$ Neuroscience Graduate Program, University of California Riverside, \\ Riverside, California 92521, and ${ }^{4}$ Department of Pediatrics, University of California Irvine, Irvine, California 92350
}

Astrocyte-derived factors can control synapse formation and functions, making astrocytes an attractive target for regulating neuronal circuits and associated behaviors. Abnormal astrocyte-neuronal interactions are also implicated in neurodevelopmental disorders and neurodegenerative diseases associated with impaired learning and memory. However, little is known about astrocyte-mediated mechanisms that regulate learning and memory. Here, we propose astrocytic ephrin-B1 as a regulator of synaptogenesis in adult hippocampus and mouse learning behaviors. We found that astrocyte-specific ablation of ephrin-B1 in male mice triggers an increase in the density of immature dendritic spines and excitatory synaptic sites in the adult CA1 hippocampus. However, the prevalence of immature dendritic spines is associated with decreased evoked postsynaptic firing responses in CA1 pyramidal neurons, suggesting impaired maturation of these newly formed and potentially silent synapses or increased excitatory drive on the inhibitory neurons resulting in the overall decreased postsynaptic firing. Nevertheless, astrocytespecific ephrin-B1 knock-out male mice exhibit normal acquisition of fear memory but enhanced contextual fear memory recall. In contrast, overexpression of astrocytic ephrin-B1 in the adult CA1 hippocampus leads to the loss of dendritic spines, reduced excitatory input, and impaired contextual memory retention. Our results suggest that astrocytic ephrin-B1 may compete with neuronal ephrin-B1 and mediate excitatory synapse elimination through its interactions with neuronal $\mathrm{EphB}$ receptors. Indeed, a deletion of neuronal EphB receptors impairs the ability of astrocytes expressing functional ephrin-B1 to engulf synaptosomes in vitro. Our findings demonstrate that astrocytic ephrin-B1 regulates long-term contextual memory by restricting new synapse formation in the adult hippocampus.

Key words: astrocyte; contextual learning; endocytosis; ephrin-B1; hippocampus; synapse

\section{Significance Statement}

These studies address a gap in our knowledge of astrocyte-mediated regulation of learning and memory by unveiling a new role for ephrin-B1 in astrocytes and elucidating new mechanisms by which astrocytes regulate learning. Our studies explore the mechanisms underlying astrocyte regulation of hippocampal circuit remodeling during learning using new genetic tools that target ephrin-B signaling in astrocytes in vivo. On a subcellular level, astrocytic ephrin-B1 may compete with neuronal ephrin-B1 and trigger astrocyte-mediated elimination of EphB receptor-containing synapses. Given the role EphB receptors play in neurodevelopmental disorders and neurodegenerative diseases, these findings establish a foundation for future studies of astrocyte-mediated synaptogenesis in clinically relevant conditions that can help to guide the development of clinical applications for a variety of neurological disorders.

\section{Introduction}

Hippocampal circuits are well known for their role in the formation of new memories and lifelong learning (Milner et al., 1998; Neves et al., 2008). However, it is unclear how the circuits are regulated at the level of individual synapses. During contextual learning hippocampal synapses undergo activity-dependent growth, elimination, or maturation in a synapse-specific manner. In particular, CA1 hippocampal neurons have been implicated in 
contextual learning (Strekalova et al., 2003), which triggers a recruitment of AMPARs to specific dendritic domains of CA1 neurons (Matsuo et al., 2008), whereas ablation of synaptic NMDARs in the CA1 hippocampus was reported to impact learning (Tsien et al., 1996).

Although the role of astrocytes in hippocampal-dependent learning is not completely understood, astrocyte dysfunctions are implicated in synapse pathologies associated with intellectual disabilities and learning impairments (Ballas et al., 2009; Jacobs et al., 2010; Lioy et al., 2011; Higashimori et al., 2016). Astrocytes are known to control the development and maintenance of synapses (Clarke and Barres, 2013; Allen and Eroglu, 2017). Several astrocyte-secreted factors, such as thrombospondin-1, glypicans and Hevin, are known to affect both synapse structure and function by regulating synapse formation, recruiting AMPARs, and modulating synaptic functions during development (Ullian et al., 2001; Christopherson et al., 2005; Eroglu et al., 2009; Kucukdereli et al., 2011; Allen et al., 2012). Astrocytic processes are also found in direct contact with synapses, suggesting that contact-mediated glial-neuronal interactions may also play a role in synapses (Araque et al., 1999). Indeed, neurons directly contacting astrocytes show robust synaptogenesis, whereas neurons treated with only astrocyte-conditioned medium form fewer synapses (Ullian et al., 2001).

In addition to promoting synapse formation through a contact-mediated mechanism (Hama et al., 2004; Barker et al., 2008; Garrett and Weiner, 2009), astrocytes can also regulate synapse elimination through phagocytosis (Chung et al., 2013). Earlier electron microscopy studies also revealed possible transendocytosis between hippocampal neurons and astrocytes (Spacek and Harris, 2004). Indeed, astrocytes have been implicated in pruning and clearing unwanted axons and synapses during synapse development (Lauterbach and Klein, 2006; Eroglu and Barres, 2010; Chung et al., 2013), allowing for increased efficiency of neuronal transmission and refinement of functional circuits (Cowan et al., 1984; Luo and O'Leary, 2005). Hippocampus maintains a high level of synaptic plasticity in the adult brain and can undergo synapse growth or elimination based on the fluctuations in neuronal activity (Yasumatsu et al., 2008).

Here we present new evidence suggesting a role of astrocytic ephrin-B1 (astro-ephrin-B1) in regulating hippocampal circuits in the adult mouse brain. Ephrin-B1 is a membrane-bound protein that acts as a ligand for the EphB receptors. EphB/ephrin-B interactions activate bidirectional signaling in both cells expressing EphB receptor and ephrin-B (Bush and Soriano, 2009; Sloniowski and Ethell, 2012; Xu and Henkemeyer, 2012). Transsynaptic ephrin-B-EphB interactions between neurons are important for the formation and maintenance of synapses in the mouse brain (Ethell et al., 2001; Henderson et al., 2001; Takasu et al., 2002; Henkemeyer et al., 2003; Grunwald et al., 2004). However, how ephrin-B1 expression in astrocytes may influence synapse formation and maintenance is still unclear.

Our in vivo studies demonstrate that astrocyte-specific ephrin-B1 deletion in the adult hippocampus of ERT2-Cre ${ }^{G F A P}$ ephrin-B1 ${ }^{\text {flox/y }}$ male mice triggers an increase in the number of synaptic sites and immature dendritic spines in CA1 hippocampus. However, de-

The authors declare no competing financial interests.

*J.K. and A.Q.N. contributed equally to this work.

Correspondence should be addressed to Dr. Iryna M. Ethell, Division of Biomedical Sciences, University of California Riverside School of Medicine, Riverside, California 92521. E-mail: iryna.ethell@medsch.ucr.edu.

DOI:10.1523/JNEUROSCI.3618-17.2018

Copyright $\odot 2018$ the authors $\quad 0270-6474 / 18 / 385711-17 \$ 15.00 / 0$ spite the increase in synapse numbers, we see reduced postsynaptic firing responses in the CA1 hippocampus and decreased number of mature excitatory synapses. Surprisingly, astroephrin-B1 knock-out mice exhibit normal acquisition of fear memory but enhanced contextual fear memory recall and renewal. In contrast, overexpression of ephrin-B1 in the adult astrocytes using adeno-associated virus (AAV) approach leads to a reduced contextual memory recall most likely due to synapse elimination. Astro-ephrin-B1 may compete with neuronal ephrin-B1 and trigger astrocyte-mediated elimination of EphB receptor-containing synapses via trans-endocytosis. Indeed, a deletion of synaptic EphB receptors impairs the ability of astrocytes expressing functional ephrin-B1 to engulf synaptosomes. Our studies suggest that astro-ephrin-B1 regulates the formation of contextual memories by restricting synapse formation in the adult hippocampus.

\section{Materials and Methods}

Mice. B6.Cg-Tg(GFAP-cre/ERT2)505Fmv/J (ERT2-Cre ${ }^{G F A P}$; RRID: IMSR_JAX:012849) male mice were crossed with 129S-Efnb1 ${ }^{\text {tm } 1 \text { Sor } / J ~ f e-~}$ male mice (ephrin-B1 $1^{\text {flox/+ }}$; RRID:IMSR_JAX:007664) to obtain ERT2Cre ${ }^{G F A P}$ ephrin-B1 $1^{\text {flox/y }}(\mathrm{KO})$, or ERT2-Cre ${ }^{\text {GFAP }}$ (WT) male mice. Adult WT and KO littermates received tamoxifen (TAM) intraperitoneally (1 $\mathrm{mg}$ in $5 \mathrm{mg} / \mathrm{ml} \mathrm{1:9} \mathrm{ethanol/sunflower} \mathrm{seed} \mathrm{oil} \mathrm{solution)} \mathrm{once} \mathrm{a} \mathrm{day} \mathrm{for} 7$ consecutive days (Fig. 1A). We did not detect any changes in ephrin-B1 levels in astrocytes or neurons in ERT2-Cre ${ }^{G F A P}$ ephrin-B1 ${ }^{\text {flox/y }}$ noninjected or injected with sunflower seed oil without tamoxifen as previously reported (Nikolakopoulou et al., 2016). Ephrin-B1 immunoreactivity was analyzed in ERT2-Cre ${ }^{G F A P}$ ephrin-B1 ${ }^{\text {flox/y }}(\mathrm{KO})$ and ERT2-Cre ${ }^{G F A P}$ (WT) mice (Fig. 1B). Astrocyte-specific Cre expression was confirmed in tamoxifen-treated ERT2-Cre ${ }^{G F A P}$ using Rosa-CAG-LSL-tdTomato reporter mice (CAG-tdTomato; RRID:IMSR_JAX:007909; Fig. 1C). Ephrin-B1 immunoreactivity was observed in cell bodies and dendrites of CA1 neurons but not hippocampal astrocytes of tamoxifen-treated $\mathrm{KO}$ mice (Fig. $1 C-G$ ). There were no changes in ephrin-B1 levels in astrocytes and neurons of untreated and tamoxifen-treated WT animals. Genotypes were confirmed by PCR analysis of genomic DNA isolated from mouse tails. Mice were maintained in an AAALAC accredited facility under $12 \mathrm{~h}$ light/dark cycle and fed standard mouse chow. All mouse studies were done according to NIH and Institutional Animal Care and Use Committee guidelines.

Stereotaxic microinjections. To induce expression of ephrin-B1 and tdTomato in hippocampal astrocytes we used adeno-associated viruses AAV7s containing AAV7.GfaABC1D.ephrin-B1.SV40 or AAV7.GfaABC1D. tdTomato.SV40, respectively (both obtained from UPenn Vector Core, http://www.med.upenn.edu/gtp/vectorcore). Viral titers were $7.56 \times 10^{12}$ viral particles (VP)/ml for AAV7.GfaABC1D.ephrin-B1.SV40 (AAVephrin-B1) and $4.46 \times 10^{12} \mathrm{VP} / \mathrm{ml}$ for AAV7.GfaABC1D.tdTomato.SV40 (AAV-tdTomato). VP were further concentrated with Amicon ultra- 0.5 centrifugal filter (UFC505024, Sigma-Aldrich) pretreated with $0.1 \%$ Pluronic F-68 nonionic surfactant (24040032, ThermoFisher). VP were stereotaxically injected into the dorsal hippocampus of adult postnatal day $(\mathrm{P})$ 70-90 C57BL/6 or Thy1-EGFP mice as follows. Mice were anesthetized by intraperitoneal injections of ketamine/xylazine mix $(80 \mathrm{mg} / \mathrm{kg}$ ketamine and $10 \mathrm{mg} / \mathrm{kg}$ xylazine). Adequate anesthesia was assessed by paw pad pinch test, respiratory rhythm, righting reflex, and/or loss of corneal reflex. Animals received craniotomies ( $1 \mathrm{~mm}$ diameter) and stereotaxic injections were performed at $2.5 \mathrm{~mm}$ posterior to bregma, $1.0 \mathrm{~mm}$ lateral to midline, and 1.2 $\mathrm{mm}$ from the pial surface. Control mice were bilateral injected with $2 \mu \mathrm{l}$ of $1.16 \times 10^{13} \mathrm{VP} / \mathrm{ml}$ AAV7.GfaABC1D.tdTomato.SV40 and experimental animals received $1 \mu \mathrm{l}$ of $3.78 \times 10^{13} \mathrm{VP} / \mathrm{ml}$ AAV7,GfaABC1D.ephrinB1.SV40 $+1 \mu \mathrm{l}$ of $2.32 \times 10^{13} \mathrm{VP} / \mathrm{ml}$ AAV7.GfaABC1D.tdTomato.SV40. Postsurgery mice received $0.3 \mathrm{ml}$ of buprenorphine by subcutaneous injection every $8 \mathrm{~h}$ for $48 \mathrm{~h}$ as needed for pain and animals were allowed to recover for $14 \mathrm{~d}$ before fear conditioning tests and/or immunohistochemistry.

Immunohistochemistry. Animals were anesthetized with isoflurane and transcardially perfused first with $0.9 \% \mathrm{NaCl}$ followed by fixation with $4 \%$ 
A

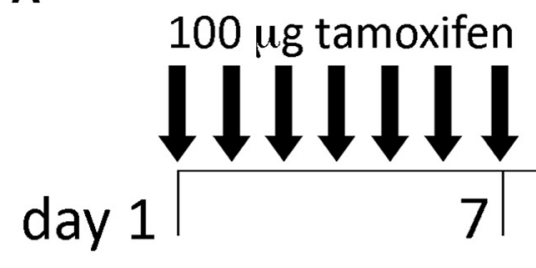

day 1

7

\section{Adult mice}

IHC: (vGlut1, GAD65)

Dendritic spine analysis

Electrophysiology

Behavior
B

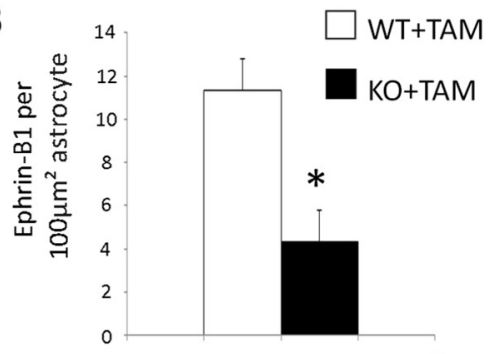

C KO+TAM tdTomato ephrin-B1

SP
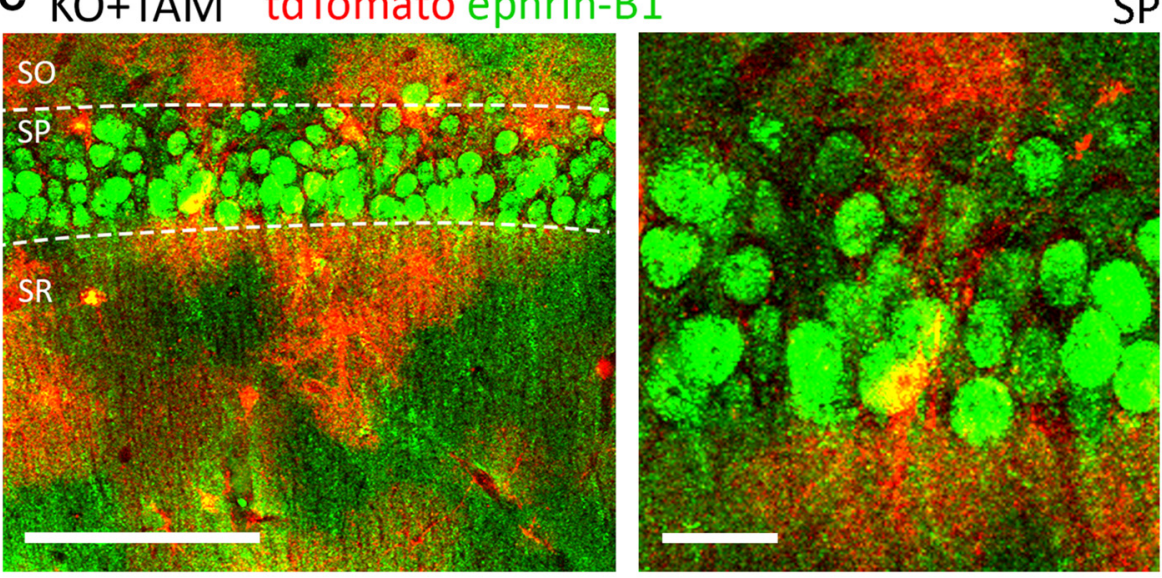

SR

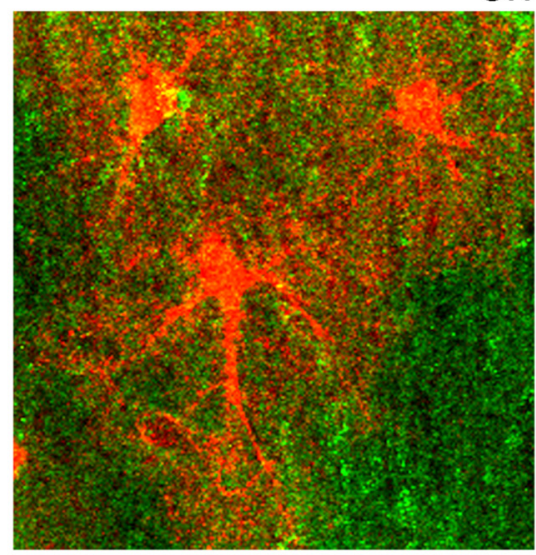

D GFAP ephrin-B1

WT+TAM E GFAP ephrin-B1
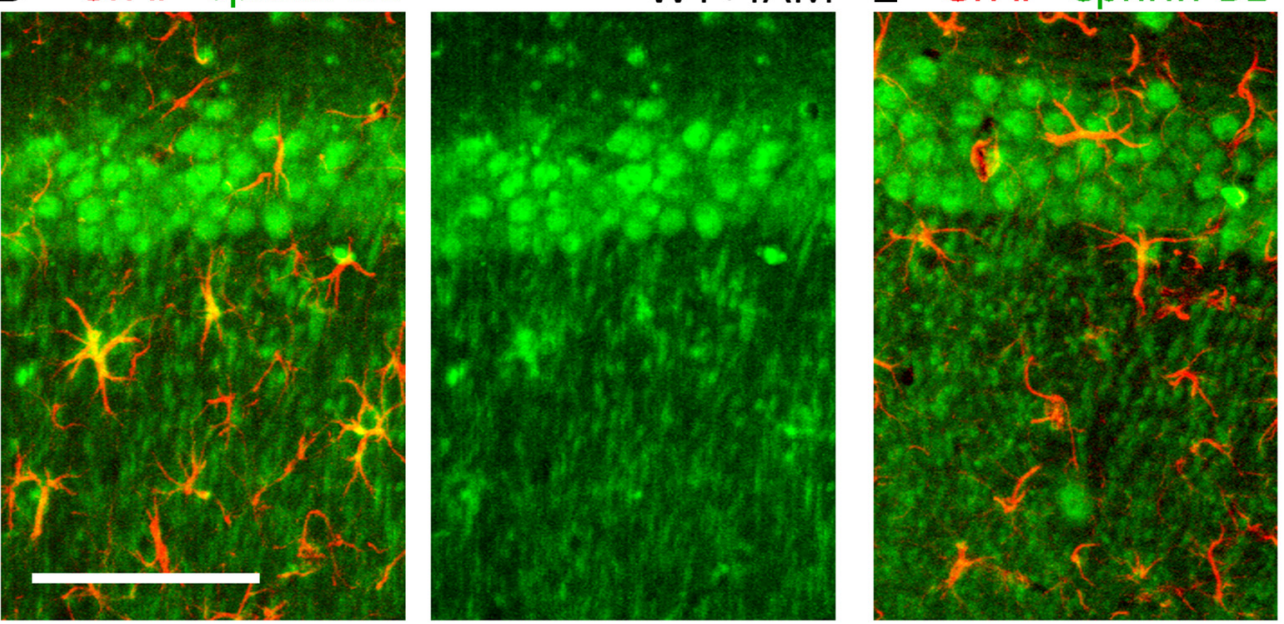

KO+TAM

\section{F GFAP ephrin-B1 ephrin-B1}



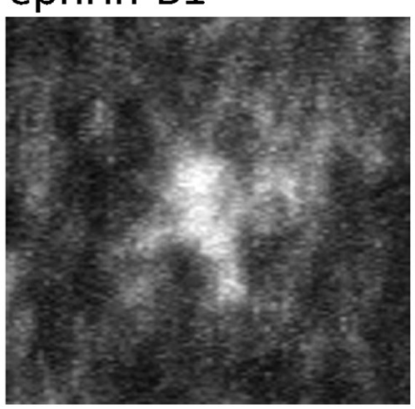

\section{G GFAP ephrin-B1 ephrin-B1}

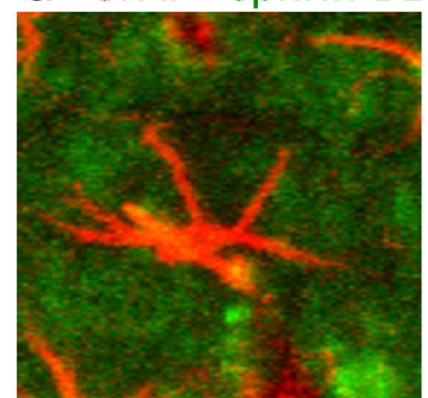

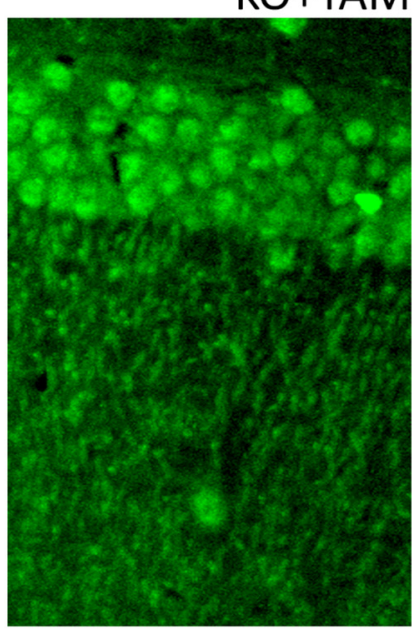

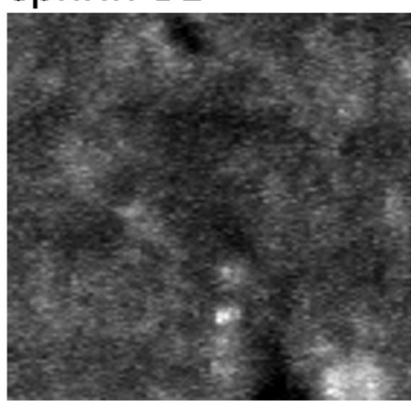

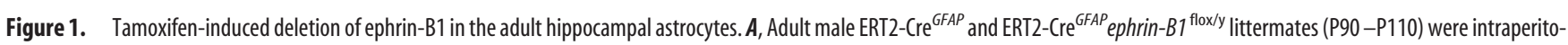
neally injected with $1 \mathrm{mg}$ of tamoxifen once a day for 7 consecutive days. Immunohistochemistry, spine labeling, electrophysiology, and behavior tests were performed $14 \mathrm{~d}$ after first injection. $B$, Astrocytic ephrin-B1 immunoreactivity was significantly reduced in the hippocampus of K0+TAM compared with WT+TAM mice $\left(n=3\right.$ mice, $t$ test, $\left.{ }^{*} p<0.05\right)$. C, Max projection confocal images of the CA1 hippocampus in tamoxifen-injected ERT2-Cre ${ }^{G F A P}$ stop ${ }^{\text {flox }}$ tdTomato mice show tdTomato expression in astrocytes of SR, but not in CA1 neurons of the SP area. Ephrin-B1 immunoreactivity was detected in cell bodies (green, SP) and dendrites (green, SR) of CA1 neurons but not in tdTomato-positive astrocytes (red). Low-magnification. Scale bars: $100 \mu \mathrm{m}$; high-magnification, $20 \mu \mathrm{m}$. D, E, Max projection confocal images show GFAP (red) and ephrin-B1 (green) immunoreactivity in the CA1 hippocampus. Scale bar, $100 \mu \mathrm{m}$. F, G, High-magnification images show ephrin-B1 immunoreactivity in astrocytes of WT + TAM but not K0 + TAM mice. Ephrin-B1 is detected in dendrites of CA1 neurons verifying that deletion of ephrin-B1 is specific to astrocytes. Scale bar, $25 \mu \mathrm{m}$. 
paraformaldehyde in $0.1 \mathrm{M}$ PBS, $\mathrm{pH}$ 7.4. Brains were postfixed overnight with $4 \%$ paraformaldehyde in $0.1 \mathrm{~m}$ PBS and $100 \mu \mathrm{m}$ coronal brain sections were cut with a vibratome. Excitatory presynaptic boutons were labeled by immunostaining against vesicular glutamate transporter 1 (vGlut1) using rabbit anti-vGlut1 antibody $(0.25 \mathrm{mg} / \mathrm{ml}$; Invitrogen, Catalog \#482400; RRID:AB_2533843), postsynaptic sites were identified with mouse anti-postsynaptic density-95 (PSD95) antibody ( $1.65 \mu \mathrm{g} /$ ml; Invitrogen, Catalog\# MA1-045; RRID:AB_325399). Inhibitory neurons were detected with mouse anti-glutamic acid decarboxylase 65 (GAD65) antibody ( $10 \mu \mathrm{g} / \mathrm{ml}$; BD PharMingen, Catalog \#559931; RRID:AB_397380). Astrocytes were identified by immunolabeling against glial fibrillary acidic protein (GFAP) using mouse anti-GFAP antibody (1:500; Sigma-Aldrich, Catalog \#G3893; RRID:AB_477010), and ephrin-B1 levels were detected by immunostaining with goat anti-ephrin-B1 antibody ( $20 \mu \mathrm{g} / \mathrm{ml}$; R\&D Systems, Catalog \#AF473; RRID:AB_2293419). Secondary antibodies used were AlexaFluor 594-conjugated donkey anti-mouse IgG (4 mg/ml; Invitrogen, Catalog \#A-21203; RRID:AB_141633), AlexaFluor 647-conjugated donkey anti-rabbit IgG (4 mg/ml; Invitrogen, Catalog \#A-31573; RRID: AB_2536183), AlexaFluor 647-conjugated donkey anti-goat IgG (4 mg/ml; Invitrogen, Catalog \#A-21447; RRID:AB_141844), or AlexaFluor 488-conjugated donkey anti-goat IgG (4 mg/ml; Invitrogen, Catalog \#A-11055; RRID:AB_2534102). Sections were mounted on slides with Vectashield mounting medium containing DAPI (Vector Laboratories, Catalog \#H-1200; RRID:AB_2336790).

Confocal imaging and analysis. Confocal images of the stratum radiatum (SR) and stratum lacunosum-moleculare (SLM) layers of CA1 hippocampus were taken with a Leica SP2 confocal laser-scanning microscope. A series of high-resolution optical sections $(1024 \times 1024$ pixel format) were captured with a $20 \times$ or $63 \times$ water-immersion objective (1.2 numerical aperture) and $1 \times$ zoom at $1 \mu \mathrm{m}$ step intervals $(z$-stack of 10 optical sections). All images were acquired under identical conditions. Each $z$-stack was collapsed into a single image by projection, converted to a tiff file, encoded for blind analysis, and analyzed using ImageJ Software. Three adjacent projections from SR were analyzed per each hippocampus from at least three animals per group. Cell area, integrated fluorescent intensity, and cell perimeter were determined for each GFAPpositive and ephrinB1-positive cell (100-300 astrocytes, $z$-stacks at least 10 optical images, $5-11$ brain slices, $3-4$ mice per group). For the analysis of vGlut1, GAD65, and PSD95 immunolabeling, at least six sequential images were captured for selected area at $1 \mu \mathrm{m}$ step intervals, each image in the series was threshold-adjusted to identical levels $(0-160$ intensity) and puncta $\left(0.5-10 \mu \mathrm{m}^{2}\right)$ were measured using ImageJ software (RRID:SCR_003070). Cell body labeling was excluded from the analysis. Three adjacent areas from SR and SLM were imaged and analyzed per each hippocampus from at least three animals per group. Statistical analysis was performed with one-way ANOVA followed by Tukey post hoc analysis using GraphPad Prism 6 software (RRID:SCR_002798), data represent mean \pm SEM.

Dendritic spine analysis. Animals were anesthetized with isoflurane and transcardially perfused with $4 \%$ paraformaldehyde in $0.1 \mathrm{M}$ PBS, $\mathrm{pH}$ 7.4. Brains were postfixed for $2 \mathrm{~h}$ in $4 \%$ paraformaldehyde in 0.1 M PBS and $100 \mu \mathrm{m}$ coronal sections were cut with a vibratome. Dendritic spines were labeled using a DiOlistic approach (Henkemeyer et al., 2003). Tungsten particles coated with fluorescent lipophilic dye 1,1'dioctadecyl-3,3,3',3'-tetramethyl-indocarbocyanine perchlorate (DiI; D282, Invitrogen) were delivered by helium-powered ejection (Bio-Rad Helios Gene Gun System) into hippocampal slices. Labeled neurons were imaged using a LSM 510 Carl Zeiss confocal microscope. Ten to 15 DiI-labeled neurons were randomly selected per group and dendrites were imaged using a $63 \times$ objective $(1.2 \mathrm{NA}), 1 \times$ zoom. Threedimensional fluorescent images were created by the projection of each $z$-stack containing 50-100 high-resolution optical serial sections $(1024 \times 1024$ pixel format) taken at $0.5 \mu \mathrm{m}$ intervals in the $x-y$ plane. Quantifications of the spine density (spines per $10 \mu \mathrm{m}$ dendrite), lengths $(\mu \mathrm{m})$, and volumes $\left(\mu \mathrm{m}^{3}\right)$ were performed using Neurolucida 360 software (MicroBrightField; RRID:SCR_001775). Statistical analysis was performed with one-way ANOVA followed by Tukey post hoc analysis using GraphPad Prism 6 software (RRID:SCR_002798), data represent mean \pm SEM.

Astrocyte cultures. Astrocytes were isolated from Cre ${ }^{G F A P}$ ephrin$B 1^{\text {flox/y }}$ or WT mouse hippocampi at postnatal day (P)0-P1 as previously described (Barker et al., 2008). Hippocampi were treated with $0.1 \%$ trypsin/EDTA solution for $25 \mathrm{~min}$ at $37^{\circ} \mathrm{C}$, and mechanically dissociated. Cells were plated on cell culture flasks and cultured in DMEM containing $10 \%$ FCS and $1 \%$ pen-strep, $<10 \% \mathrm{CO}_{2}$ atmosphere at $37^{\circ} \mathrm{C}$. To enrich astrocyte cultures ( $>95 \%$ astrocytes) cells were shaken after $4 \mathrm{~d}$ in vitro (DIV) for $1 \mathrm{~h}$. After shaking, the medium was removed and cells were washed twice with $0.1 \mathrm{M}$ PBS, pH 7.4. Cells were then treated with $0.1 \%$ trypsin/EDTA solution for $20 \mathrm{~min}$ at $37^{\circ} \mathrm{C}$ and plated on $10 \mathrm{~cm}$ Petri dishes with DMEM containing 10\% FBS. Once confluent astrocytes were detached with trypsin and plated on six-well plates at a density of 330,000 cells per plate and cultured for $2 \mathrm{~d}$ before being transfected with $p E G F P$, $p E G F P$, and $p c D N A$-ephrin-B1, or $p E G F P$ and $p c D N A$-Cre plasmids using Lipofectamine according to the manufacturer's instructions (Invitrogen, 11668-019).

Mixed neuron-astrocyte cultures. Cultures of hippocampal neurons were prepared from embryonic day (E) 15 pups. Hippocampal cells were treated with papain $(0.5 \mathrm{mg} / \mathrm{ml})$ and DNase $(0.6 \mu \mathrm{g} / \mathrm{ml})$ for $20 \mathrm{~min}$ at $37^{\circ} \mathrm{C}$, mechanically dissociated, and then plated on glass coverslips precoated with poly-D-lysine $\left(0.5 \mathrm{mg} / \mathrm{ml}\right.$ in $\left.\mathrm{H}_{2} \mathrm{O}\right)$ and laminin $(5 \mu \mathrm{g} / \mathrm{ml}$ in PBS). The hippocampal cells were cultured in neurobasal medium with $25 \mu \mathrm{M}$ glutamine, $1 \%$ penicillin-streptomycin, and B27 supplement (Invitrogen) under $5 \% \mathrm{CO}_{2} / 10 \% \mathrm{O}_{2}$ at $37^{\circ} \mathrm{C}$. Astrocytes were isolated from mouse hippocampi at $\mathrm{P} 0-\mathrm{P} 3$ as described above. Primary astrocytes were cultured for $14 \mathrm{~d}$, then transfected with $p E G F P$, $p E G F P$, and $p c D N A$ ephrin-B1, or $p E G F P$ and $p c D N A-C r e$ and added to 13 DIV neuronal cultures for $24 \mathrm{~h}$. Fourteen DIV cultures were washed with $0.1 \mathrm{M}$ PBS then fixed with $2 \%$ paraformaldehyde in $0.1 \mathrm{~m}$ PBS for $30 \mathrm{~min}$ and permeabilized with $0.1 \%$ Triton X in $0.1 \mathrm{M}$ PBS for 15 min before immunolabeling astrocytes and synapses. Presynaptic boutons were labeled by immunostaining for the presynaptic marker synapsin using rabbit antisynapsin-1 antibody $(0.4 \mu \mathrm{g} / \mathrm{ml}$; Millipore, Catalog \#AB1543; RRID: AB_90757) and postsynaptic sites with mouse anti-PSD95 antibody $(1.65 \mu \mathrm{g} / \mathrm{ml}$; Invitrogen, Catalog \#MA1-045; RRID:AB_325399). Astrocytes were identified by immunolabeling against GFAP using mouse anti-GFAP antibody (1:500; Sigma-Aldrich, Catalog \#G3893; RRID: AB_477010), neurons by immunostaining against microtubule-associated protein 2 (MAP2) using mouse anti-MAP2 antibody $(16.6 \mu \mathrm{g} / \mathrm{ml}$; Sigma-Aldrich, Catalog \#M4403; RRID:AB_477193) and ephrin-B1 expression was determined by immunostaining with goat antiephrin-B1 antibody ( $20 \mu \mathrm{g} / \mathrm{ml}$; R\&D Systems, Catalog \#AF473; RRID: AB_2293419). Transfected cells were identified by GFP fluorescence. Secondary antibodies used were AlexaFluor 594-conjugated donkey anti-mouse IgG (4 mg/ml; Invitrogen, Catalog \#A-21203; RRID: AB_141633), AlexaFluor 647-conjugated donkey anti-rabbit IgG (4 mg/ ml; Invitrogen, Catalog \#A-31573; RRID:AB_2536183), or AlexaFluor 488-conjugated donkey anti-goat IgG ( $4 \mathrm{mg} / \mathrm{ml}$; Invitrogen, Catalog \#A11055; RRID:AB_2534102). Sections were mounted on slides with Vectashield mounting medium containing DAPI (Vector Laboratories, Catalog \#H-1200; RRID:AB_2336790). Fluorescent images were captured with a Leica SP5 confocal laser-scanning microscope using a $63 \times$ oil-immersion objective ( 1.2 numerical aperture) and $1 \times$ zoom at $1 \mu \mathrm{m}$ step intervals ( $z$-stack of at least 5 optical sections). Each $z$-stack was collapsed into a single image by projection, converted to a tiff file, and encoded for blind analysis. Synaptic puncta were quantified within the area of GFP-expressing astrocytes using ImageJ software (RRID:nif-0000_30467). Data represent mean \pm SEM.

Ephrin-B1 mutants. Mutagenesis was performed using QuikChange Lighting Multi Site-Directed Mutagenesis Kit (Catalog \#210513, Agilent Technologies) to generate ephrin-B1Y294F, ephrin-B1Y310F, and ephrin-B1Y294F/Y310F mutants by changing tyrosine (TAC) at positions 294 and 310 to phenylalanine (TTC) using $p c D N A$ plasmid-containing mouse ephrin-B1 cDNA.

Synaptosome purification. Synaptosome purification was performed as previously described (Hollingsworth et al., 1985). Hippocampal tissues from adult WT or EphB1,2,3 KO mice were homogenized in $1 \mathrm{ml}$ syn- 
aptosome buffer (in mM: $124 \mathrm{NaCl}, 3.2 \mathrm{KCl}, 1.06 \mathrm{KH}_{2} \mathrm{PO}_{4}, 26 \mathrm{NaHCO}_{3}$, $1.3 \mathrm{MgCl}_{2}, 2.5 \mathrm{CaCl}_{2}, 10$ glucose, 20 HEPES). Homogenates were filtered through a $100 \mu \mathrm{m}$ nylon net filter (NY1H02500, Millipore) and $5 \mu \mathrm{m}$ nylon syringe filter (SF15156, Tisch International). Homogenate flow through was collected and synaptosomes were spun down at $10,000 \times g$, $4^{\circ} \mathrm{C}$, for $30 \mathrm{~min}$. Synaptosomes were resuspended in $800 \mu \mathrm{l}$ synaptosome buffer. To confirm synaptosome enrichment, levels of synapsin-1, PSD95, and histone deacetylase (HDAC I) were analyzed in tissue homogenates and synaptosome fractions with Western blot analysis. Synaptosomes for engulfment assays were also stained with 5\% (w/v) DiI (D282, Invitrogen) in DMSO for $10 \mathrm{~min}$.

Western blot analysis. Tissue homogenate or purified synaptosome samples were centrifuged at $10,000 \times g, 4^{\circ} \mathrm{C}$, for $30 \mathrm{~min}$, pellets were resuspended in lysis buffer $(50 \mathrm{~mm}$ Tris, $100 \mathrm{~mm} \mathrm{NaCl}, 2 \%$ Triton X-100, $10 \mathrm{~mm}$ EDTA) containing $2 \%$ protease inhibitor cocktail (P8340, SigmaAldrich) and incubated for $2 \mathrm{~h}$ at $4^{\circ} \mathrm{C}$. Samples were added to $2 \mathrm{X}$ Laemmli Buffer (S3401, Sigma-Aldrich) and run on an 8-16\% Tris-Glycine Gel (EC6045BOX, Invitrogen). Protein samples were transferred onto a nitrocellulose blotting membrane (10600007, GE Healthcare). Blots were blocked with 5\% milk in TBS (10 mM Tris, $150 \mathrm{~mm} \mathrm{NaCl}$, pH 8.0) followed by immunostaining with mouse anti-PSD95 ( $1.65 \mu \mathrm{g} / \mathrm{ml}$; Invitrogen, Catalog \#MA1-045; RRID:AB_325399), rabbit anti-GluA1 (1:100; Millipore, Catalog \#AB1504; RRID:AB_2113602), rabbit anti-GluA2/3 $(0.1 \mu \mathrm{g} / \mathrm{ml}$; Millipore, Catalog \#AB1506; RRID:AB_90710), rabbit antiHDAC I $(0.40 \mu \mathrm{g} / \mathrm{ml}$; Santa Cruz Biotechnologies, Catalog \#sc-7872; RRID:AB_2279709), rabbit anti-synapsin-1 $(0.2 \mu \mathrm{g} / \mathrm{ml}$; Millipore, Catalog \#AB1543P; RRID:AB_90757), or mouse anti-GAPDH $(0.2 \mu \mathrm{g} / \mathrm{ml}$; ThermoFisher Scientific, Catalog \#39-8600; RRID:AB_2533438) antibodies in $0.1 \%$ Tween $20 / \mathrm{TBS}$ at $4^{\circ} \mathrm{C}$ for $16 \mathrm{~h}$. Secondary antibodies used were HRP-conjugated donkey anti-mouse IgG (Jackson ImmunoResearch, Catalog \#715-035-150; RRID:AB_2340770) or HRP-conjugated goat anti-rabbit IgG (Jackson ImmunoResearch, Catalog \#111-035-003; RRID:AB_2313567). Blots were incubated in ECL 2 Western Blotting Substrate (Pierce, Catalog \#80196) and a signal was collected with CLXPosure film (34090, Pierce). Band density was analyzed by measuring band and background intensity using Adobe Photoshop CS5.1 software (RRID:SCR_014199). Statistical analysis was performed with a one-way ANOVA followed by Tukey post hoc analysis using GraphPad Prism 6 software (RRID:SCR_002798). Data represent mean \pm SEM.

Engulfment assay. Astrocytes were isolated as described above. Fourteen DIV astrocytes were plated onto poly-D-lysine $(0.5 \mathrm{mg} / \mathrm{ml})$-coated coverslips at 50,000 cells per coverslip and maintained at $37^{\circ} \mathrm{C} 10 \% \mathrm{CO}_{2}$. Astrocytes were transfected $24 \mathrm{~h}$ after plating with $p c D N A-e G F P$, $p c D N A-e G F P+p c D N A 3-e p h r i n-B 1, p c D N A-e G F P+p c D N A 3-e p h r i n-$ B1Y294F, pcDNA-eGFP + pcDNA3-ephrin-B1Y310F, or pcDNA-eGFP + pcDNA3-ephrin-B1Y294/310F using Lipofectamine 2000 (Invitrogen, 11668-027). Isolated synaptosomes (see Synaptosome purification) were added to astrocyte cultures and incubated for $2-4 \mathrm{~h}$ at $37^{\circ} \mathrm{C} 10 \% \mathrm{CO}_{2}$. Astrocytes were washed with $0.1 \mathrm{M}$ PBS $\left(16 \mathrm{~mm} \mathrm{NaH}_{2} \mathrm{PO}_{4}, 96 \mathrm{~mm}\right.$ $\mathrm{Na}_{2} \mathrm{HPO}_{4}, 137 \mathrm{~mm} \mathrm{NaCl}$ ), followed by fixation for 30 min with $2 \%$ paraformaldehyde in $0.1 \mathrm{M}$ PBS. Cultures were immunostained (see Immunohistochemistry) against ephrin-B1 and imaged using a Zeiss 510 confocal microscope (see Confocal imaging and analysis). In brief, astrocytes were randomly selected per group and imaged using a $63 \times$ objective (1.2 NA) and $1 \times$ zoom. A series of 3-5 high-resolution optical sections $(1024 \times 1024)$ were taken at $0.5 \mu \mathrm{m}$ intervals in the $x-y$ plane. Synaptosome engulfment was determined by measuring integrated density of DiI-labeled synaptosomes associated with GFP-expressing astrocytes using ImageJ Software. Statistical analysis was performed with a one-way ANOVA followed by Tukey post hoc analysis using GraphPad Prism 6 software (RRID:SCR_002798). Data represent mean \pm SEM.

Fear conditioning test. Hippocampal-dependent contextual learning was assessed using a fear-conditioning paradigm as previously described (Anagnostaras et al., 2001). Two contexts were used to test contextual memory. Context A consisted of an $18 \times 18 \mathrm{~cm}$ rectangular clear Plexiglas box with 16 grated steel bars on the bottom. All trials under Context A were under white light and the scent of Quatricide TB. Context B consisted of a cylinder with a diameter of $15 \mathrm{~cm}$ and a height of $20 \mathrm{~cm}$ with $2.5 \times 2.5 \mathrm{~cm}$ checkered black and white walls. All trials in Context $\mathrm{B}$ were under altered light with fresh litter and the scent of Windex. Animals were acclimated in behavioral room for $30 \mathrm{~min}$ before each day of testing, and handled for $2 \mathrm{~min}$ for $5 \mathrm{~d}$ before subsequent testing. On day 1 the test mouse was placed in Context A and allowed to habituate to the chamber for $10 \mathrm{~min}, 1 \mathrm{~h}$ after Context A mice were habituated to Context $\mathrm{B}$ for $10 \mathrm{~min}$. The mouse was removed and separated from its home cage until all mice in that cage were habituated to both contexts. Sixteen hours after context habituation, test mice were trained to associate an unconditioned stimulus (US; $0.6 \mathrm{~mA}$ scrambled foot shock) with a conditioned stimulus (CS; $9 \mathrm{kHz}, 70 \mathrm{~dB}$ tone) in Context $\mathrm{A}$. Test mice were placed in Context A and given 3 min for habituation, followed by a $30 \mathrm{~s}$ tone (CS), which co-terminated with a $2 \mathrm{~s}$ foot shock (US). The CS-US pairing occurred five times, with a pseudorandom interval between pairings. Twenty-four hours after the training session animals were tested for their associated memory of the context (Context A) and of the CS tone (Context B). For contextual recall, mice were placed in Context A for 5 min with no sound and returned to home cage for $1 \mathrm{~h}$ before testing Context B. For tone recall test mice were placed in Context B for a total of 6 min with the CS tone playing for the final $3 \mathrm{~min}$.

For extinction of contextual memory $24 \mathrm{~h}$ after tone recall mice were placed in Context A for 10 min for 4 consecutive days. For memory reactivation, $1 \mathrm{~h}$ after the final extinction training mice were placed in Context $\mathrm{B}$ for a total of $6 \mathrm{~min}$ with the CS tone playing for the final $3 \mathrm{~min}$. For contextual memory renewal, mice were placed in Context A for $5 \mathrm{~min}$ $1 \mathrm{~h}$ after memory reactivation. Freezing behavior was measured as a percentage of time freezing using TopScan Software. GraphPad Prism 6 software (RRID:SCR_002798) was used to perform a one-way ANOVA followed by Tukey's post hoc analysis or $t$ test when appropriate. Data represent mean \pm SEM.

Electrophysiology. Adult mice (P90-P110) were used for electrophysiological experiments 2 weeks after the first tamoxifen injection. Animals were deeply anesthetized with isoflurane and decapitated. The brains were rapidly removed and immersed in ice-cold artificial CSF (ACSF) with high $\mathrm{Mg}^{2+}$ and sucrose concentration containing the following (in $\mathrm{mm})$ : $3.5 \mathrm{KCl}, 1.25 \mathrm{NaH}_{2} \mathrm{PO}_{4}, 20 \mathrm{D}(+)$-glucose, 185 sucrose, 26 $\mathrm{NaHCO}_{3}, 10 \mathrm{MgCl}_{2}$, and $0.50 \mathrm{CaCl}_{2}, \mathrm{pH} 7.4$, and saturated with $95 \%$ $\mathrm{O}_{2} / 5 \% \mathrm{CO}_{2}$. Transverse hippocampal slices $(350 \mu \mathrm{m})$ were prepared by using a vibrating blade microtome (LeicaVT1000s, Leica Microsystems) in ice-cold slicing solution bubbled with $95 \% \mathrm{O}_{2} / 5 \% \mathrm{CO}_{2}$. Slices were then transferred into a holding chamber containing oxygenated ACSF containing the following (in mM: $124 \mathrm{NaCl}, 3.5 \mathrm{KCl}, 1.25 \mathrm{NaH}_{2} \mathrm{PO}_{4}, 10$ $\mathrm{D}(+)$-glucose, $26 \mathrm{NaHCO}_{3}, 2 \mathrm{MgCl}_{2}$, and $\left.2 \mathrm{CaCl}_{2}, \mathrm{pH} 7.4\right)$ for $1 \mathrm{~h}$ at $33^{\circ} \mathrm{C}$. Slices were then transferred to a submersion recording chamber continually perfused with oxygenated ACSF at a flow rate of $1 \mathrm{ml} / \mathrm{min}$. Slices are allowed to equilibrate for $\sim 10 \mathrm{~min}$ to reach a stable baseline response before running experimental protocols. Glass microelectrodes (tip resistance $1-3 \mathrm{M} \Omega$, filled with $3 \mathrm{M} \mathrm{NaCl}$ ) were positioned in the CA1 stratum pyramidal (SP) and SR areas for extracellular recording. Synaptic responses were evoked by stimulating Schaffer collaterals with a bipolar tungsten electrode (WPI). Potentials were amplified (Axoclamp-2B, Molecular Devices), digitized at a sampling rate of $10 \mathrm{kHz}$ and analyzed off-line using pClamp (Molecular Devices) software. All electrophysiological responses were digitally filtered at $1 \mathrm{kHz}$ low-pass filter to improve signal-to-noise ratio.

Dendritic potentials typically consisted of a small presynaptic fiber volley (FV) followed by a negative field EPSP (fEPSP). The amplitude of the FV reflects the depolarization of the presynaptic terminals and the fEPSP slope reflects the magnitude of the postsynaptic dendritic depolarization. Postsynaptic neuronal firing is represented by the amplitude of the population spike (PS). PSs were calculated as the voltage difference between two positive peaks and the most negative peak of the trace.

Several protocols were conducted to test for functional changes. To examine basal synaptic transmission, input/output (I/O) curves were generated by incrementally increasing stimulation intensity, beginning at $0.15 \mathrm{~mA}$ and increasing stimulation by $0.15 \mathrm{~mA}$ until maximal somatic PS amplitudes were reached. The maximal PS amplitude was regarded as maximal neuronal output. Maximal fEPSP slope and maximal PS response were determined, along with $30-50 \%$ of maximal fEPSP slope and PS. Paired-pulse facilitation (PPF) was used to test for changes in 

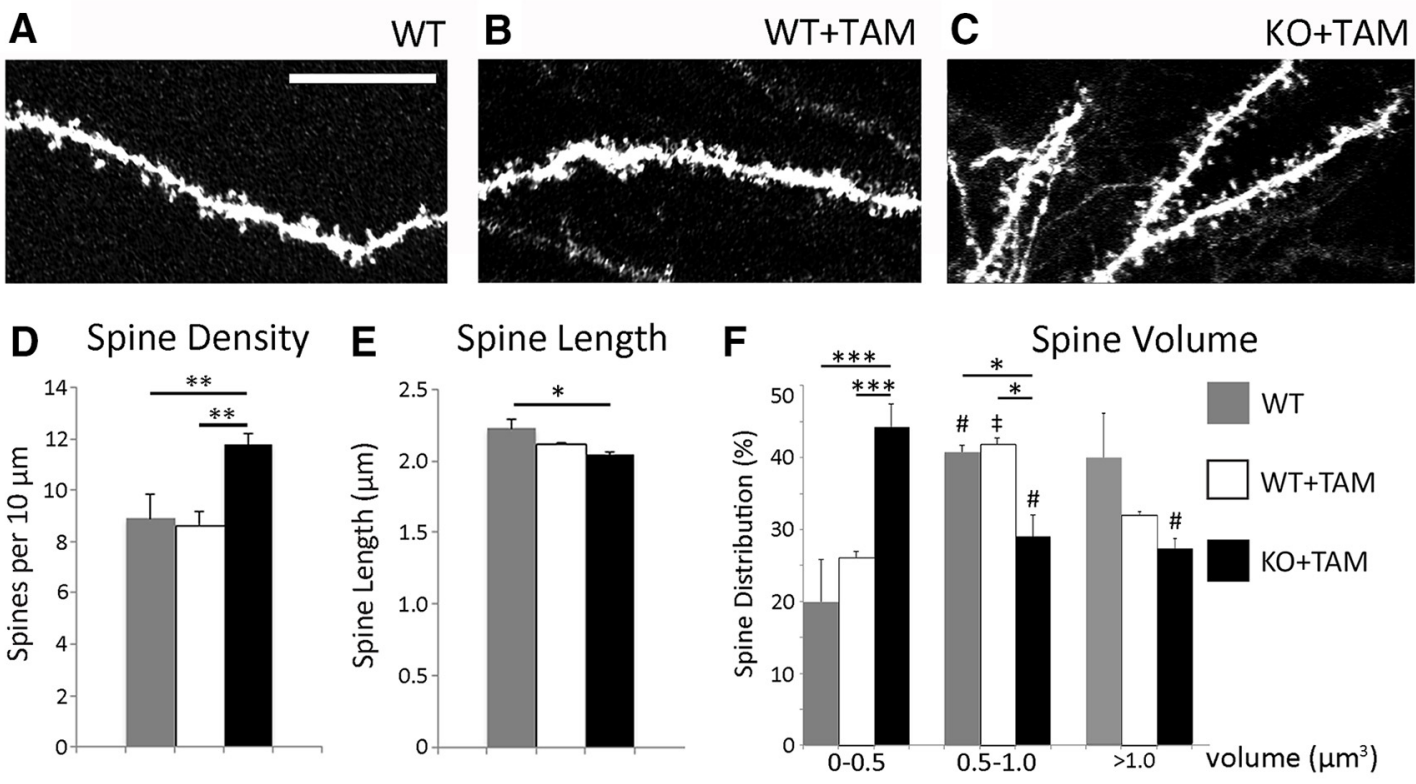

G

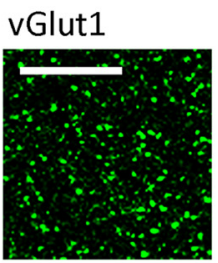

I

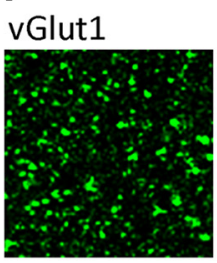

K

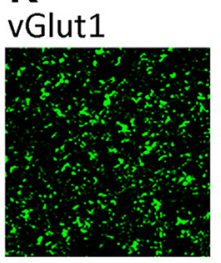

GAD65

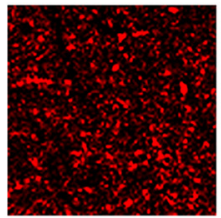

GAD65

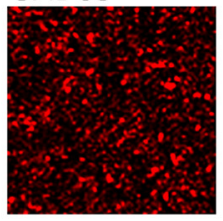

PSD95

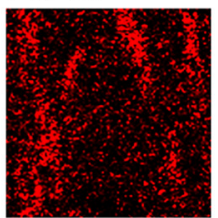

SR WT+TAM vGlut1/GAD65

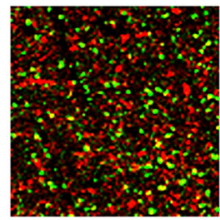

SLM WT+TAM vGlut1/GAD65

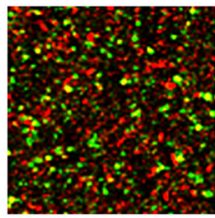

SR WT+TAM vGlut1/PSD95

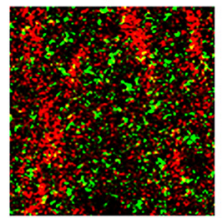

H

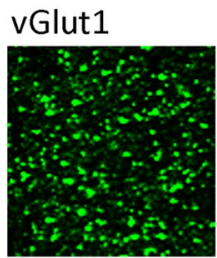

J

vGlut1

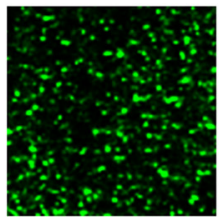

L

vGlut1

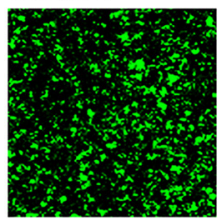

PSD95

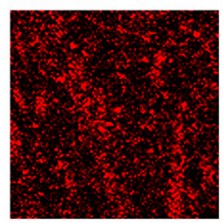

SR KO+TAM

GAD65

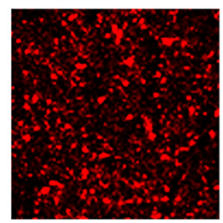

GAD65

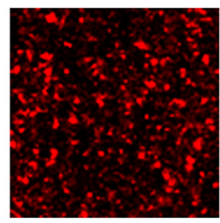
vGlut1/GAD65

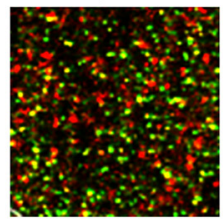

SR KO+TAM vGlut1/PSD95

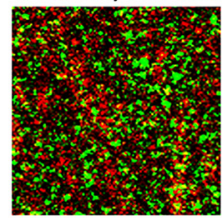

M vGlut1 immunoreactivity
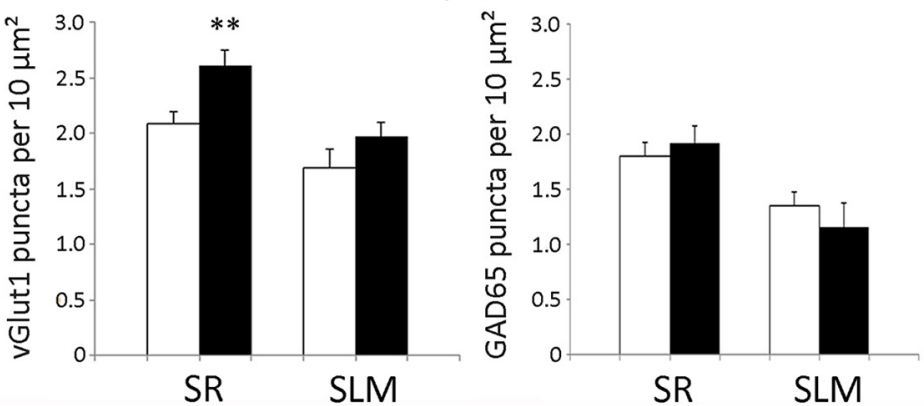

O vGlut1/PSD95 colocalization

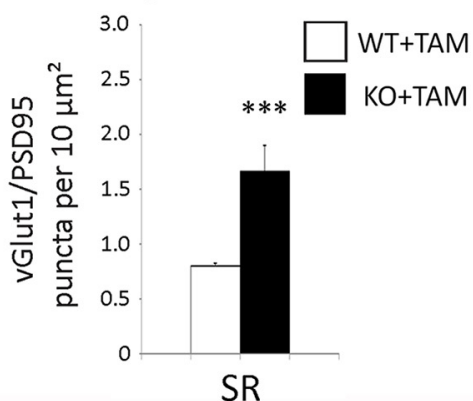

Figure 2. Synaptogenic effects of astrocyte-specific deletion of ephrin-B1 in the CA1 hippocampus. $A-C$, Max projection confocal images of Dil-labeled dendrites of CA1 neurons in the SR area of CA1 hippocampus of WT, WT + TAM, and K0 + TAM adult mice. Scale bar, $5 \mu \mathrm{m}$. D-F, Graphs show the average number of dendritic spines per $10 \mu \mathrm{m}$ dendrite $(\boldsymbol{D})$, average spine length $(\boldsymbol{E})$ and spine volume $(\boldsymbol{F})$. D. There is a significant 36\% increase in average dendritic spine density in KO + TAM mice compared with WT and WT + TAM mice; error bars represent SEM ( $n=3-6$ mice, WT: $8.91 \pm 0.93$ WT+TAM: $8.65 \pm 0.51$ vs K0+TAM: $11.77 \pm 0.46 ; F_{(2,98)}=9.199, p=0.0002$; one-way ANOVA, Tukey's post hoc test, $\left.{ }^{* *} p<0.01\right)$. (Figure legend continues.) 
presynaptic glutamate release probability. PPF was evoked by two stimuli at $30 \%$ of maximal fEPSP slope. The two stimuli were separated by varying time differences (or interpulse intervals): 20, 50, 100, 200, or $400 \mathrm{~ms}$. The second fEPSP was typically facilitated; PPF was calculated from the ratio of fEPSP2/fEPSP1 slope. To elicit paired-pulse inhibition (PPI), two stimuli were provided at $100 \%$ of max PS response and at interpulse intervals of $6,10,20,50,100$, or $200 \mathrm{~ms}$. PPI was calculated from PS2/PS1 amplitude ratio. For long-term potentiation (LTP), Schaffer collaterals were first stimulated to evoke 30\% maximal fEPSP slope for at least 10 min to obtain baseline response. LTP was then induced by the stimulation of Schaffer collaterals with 2 trains of 100 pulses at $100 \mathrm{~Hz}, 20 \mathrm{~s}$ apart. LTP was sampled at $30 \mathrm{~s}$ intervals for $60 \mathrm{~min}$ poststimulation and potentiation was calculated dividing the average slope of postinduction responses by the average slope of preinduction baseline responses.

For electrophysiological data, we used two-way ANOVA followed by Bonferroni test to evaluate the effects of astrocytic ephrin-B1 deletion on the I/O curves, PPF, PPI, and LTP. In all electrophysiological recordings data represent mean \pm SEM.

\section{Results}

Targeted ablation of ephrin-B1 in adult astrocytes triggers an increase in excitatory synapses on CA1 hippocampal neurons To determine the role of astro-ephrin-B1 in the maintenance of hippocampal circuits, we first examined whether the loss of ephrin-B1 from adult astrocyte would affect synapse numbers in CA1 hippocampus. Analysis of presynaptic and postsynaptic sites was performed in the adult hippocampus following tamoxifeninduced deletion of ephrin-B1 from astrocytes in ERT2-Cre ${ }^{G F A P}$ ephrin-B1 $1^{\text {flox/y }}$ mice. Adult ERT2-Cre ${ }^{G F A P}$ (WT) and ERT2-Cre ${ }^{\text {GFAP }}$ ephrin-B1 ${ }^{\text {flox/y }}(\mathrm{KO})$ male littermates received tamoxifen intraperitoneally ( $1 \mathrm{mg}$ in $5 \mathrm{mg} / \mathrm{ml}, 1: 9$ ethanol/sunflower seed oil) once a day for $7 \mathrm{~d}$ and analyzed 2 weeks after the first tamoxifen injection (Fig. 1A). Ephrin-B1 immunoreactivity was selectively disrupted in hippocampal astrocytes (Fig. $1 B$ ), but not neurons, of tamoxifen-treated $\mathrm{KO}$ (KO+TAM) compared with tamoxifentreated WT (WT+TAM) mice (Fig. $1 B-G$ ). Astrocyte-specific Cre expression was confirmed in tamoxifen-treated ERT2-

\footnotetext{
$\leftarrow$

(Figure legend continued.) $\quad \boldsymbol{F}$, A significant twofold increase in the proportion of dendritic spines with smaller heads (volume $0-0.5 \mu \mathrm{m}^{3}$ ) and a decrease in percentage of mature spines with volume $0.5-1.0 \mu \mathrm{m}^{3}$ are observed in K0 + TAM group compared with WT and WT + TAM groups $\left(n=3-6\right.$ mice, $F_{(14,45)}=36.19, p<0.0001$ and $F=7.701 p<0.05$, respectively; two-way ANOVA followed by Tukey's post hoc, ${ }^{*} p<0.05,{ }^{* * *} p<0.001$ ). WT and WT+TAM groups exhibit a significantly higher proportion of spines with larger heads (volume $0.5-1.0$ $\mu \mathrm{m}^{3}$ ) than the spines with smaller heads (volume $0-0.5 \mu \mathrm{m}^{3} ; n=3-6$ mice, one-way ANOVA, Tukey's post hoc test, $\# p<0.05, \neq p<0.001, F=4.462)$. K0 + TAM group shows a significantly lower proportion of spines with larger heads (volume $0.5-1.0 \mu \mathrm{m}^{3}$ and $>1.0$ $\mu \mathrm{m}^{3}$ ) than spines with smaller heads (volume $0-0.5 \mu \mathrm{m}^{3} ; n=3-6$ mice, one-way ANOVA, Tukey's posthoctest, $\# p<0.05, F=4.462$ ). $\mathbf{G}-J$, Confocal images showing vGlut1 (green) and GAD65 (red) immunolabeling in SR $(\boldsymbol{G}, \boldsymbol{H})$ and SLM $(\boldsymbol{I}, \boldsymbol{J})$ areas of the CA1 hippocampus of WT+TAM $(\boldsymbol{G}, \boldsymbol{I})$ and KO+TAM $(\boldsymbol{H}, \boldsymbol{J})$ adult mice. Scale bar, $50 \mu \mathrm{m}$. $\boldsymbol{K}, \boldsymbol{L}$, Confocal images showing vGlut1 (green) and PSD95 (red) immunolabeling in SR area of the CA1 hippocampus of WT+TAM $(\boldsymbol{K})$ and KO+TAM $(\boldsymbol{L})$ adult mice. $\boldsymbol{M}, \boldsymbol{N}$, Graphs show the density of vGlut1 and GAD65-positive puncta per $10 \mu \mathrm{m}^{2}$ of the SR and SLM areas in the CA1 hippocampus of WT + TAM and KO + TAM mice. $M$, There is a significant $25 \%$ increase in vGlut1-positive puncta in SR but not SLM area of KO + TAM compared with WT + TAM group; error bars represent SEM $\left(n=3-6\right.$ mice, WT + TAM: $2.09 \pm 0.11$ vs K0 + TAM: $2.61 \pm 0.14, t_{(64)}=2.89, p=0.0053$, $t$ test, $\left.{ }^{* *} p<0.01\right) . N$, There was no significant difference in the number of inhibitory GAD65positive puncta between WT + TAM and K0 + TAM mice $(n=3-6$ mice, WT + TAM: $1.68 \pm$ 0.18 vs KO+TAM: $1.97 \pm 0.13, t_{(64)}=1.124, p=0.2654, t$ test). $\mathbf{O}$, Graph shows the density of colocalized vGlut1 and PSD95-positive puncta per $10 \mu \mathrm{m}^{2}$ in the SR area of the CA1 hippocampus of WT + TAM and K0 + TAM mice. There is a significant increase in vGlut1/PSD95 colocalization in K0 + TAM compared with WT + TAM group, error bars represent SEM $(n=3$ mice, WT + TAM: $0.800 \pm 0.031$ vs K0+TAM: $1.666 \pm 0.232, t_{(14)}=4.198, p=0.0009, t$ test, $\left.{ }^{* * *} p<0.001\right)$.
}

Cre $^{\text {GFAP }}$ mice using Rosa-CAG-LSL-tdTomato reporter (Fig. $1 C)$. A significant $30 \%$ increase of dendritic spine density was observed in the SR area of CA1 hippocampus of $\mathrm{KO}+\mathrm{TAM}$ mice compared with untreated WT or WT+TAM adult mice (Fig. $2 D)$. However, $\mathrm{KO}$ mice had a greater proportion of spines with smaller heads $\left(0-0.5 \mu \mathrm{m}^{3}\right.$ group) and a smaller percentage of mature spines with larger head size $\left(0.5-1.0 \mu \mathrm{m}^{3}\right.$ group) than WT animals (Fig. 2F). We also observed a significant increase in the number of excitatory presynaptic boutons, which were immunolabeled against vGlut1 (Fig. $2 G-L$ ). A $25 \%$ increase in vGlut1-positive puncta was detected in the SR but not the SLM area of CA1 hippocampus of $\mathrm{KO}$ mice compared with WT mice (Fig. 2M). In addition, we observed an increase in the colocalization of presynaptic vGlut1 and postsynaptic PSD95 puncta in the SR area of CA1 hippocampus of KO mice compared with WT mice (Fig. 2O). The effects of astrocyte-specific ephrin-B1 deletion appear specific to excitatory synapses, because we did not detect significant differences in the number of inhibitory GAD65-positive puncta between the groups (Fig. 2N).

Our results suggest that astrocytic ephrin-B1 is a negative regulator of new glutamatergic synapse formation specifically in the $\mathrm{SR}$ area of adult CA1 hippocampus.

\section{Impaired postsynaptic excitability is observed in CA1 hippocampal neurons following astrocyte-specific deletion of ephrin-B1}

Increased numbers of excitatory synapses may suggest an overall increase in excitatory drive in the CA1 hippocampus. Although greater in numbers, dendritic spines were structurally less mature in $\mathrm{KO}+\mathrm{TAM}$ mice, showing a decrease in the proportion of dendritic spines with larger heads compared with untreated WT or WT+TAM mice (Fig. 2F). Therefore, we next tested the excitability of CA1 hippocampal neurons in acute hippocampal slices from adult $\mathrm{KO}+\mathrm{TAM}$ and $\mathrm{WT}+\mathrm{TAM}$ mice. To assess the effects of astrocytic ephrin-B1 deletion on basal synaptic transmission in CA1 hippocampus, synaptic responses were evoked in CA1 neurons by stimulating Schaffer collaterals with incrementally increased stimulation intensities. Input/output curves were generated by plotting presynaptic FV amplitude, postsynaptic fEPSP slope, or somatic PS amplitude as a function of increasing stimulation intensity (Fig. 3B-D). Surprisingly deletion of astrocytic ephrin-B1 did not affect presynaptic excitability, as we found no differences in the amplitude of the presynaptic FV between WT and $\mathrm{KO}$ groups (Fig. $3 B$ ). Although fEPSPs were not statistically different between the groups with potential trend toward reduced postsynaptic responses in KO animals compared with WT group (Fig. 3C), there was a significant decrease in PS amplitude (Fig. $3 D$ ). In spite a decrease in baseline excitability, short-term plasticity was also unaffected by the deletion of astro-ephrin-B1, as we found no changes in PPF (Fig. 3E) and PPI (Fig. 3F) responses between WT and KO groups. NMDAR-dependent LTP (Harris et al., 1984) was also unaffected following astrocytic ephrin-B1 deletion, as we observed similar 20\% potentiation 50-60 min poststimulation of Schaffer collaterals with 2 trains of 100 pulses in both WT and KO hippocampal slices (Fig. 3G).

Together our findings show that despite the increase in the number of excitatory synapses, CA1 pyramidal neurons showed a decrease in postsynaptic firing following astrocyte-specific deletion of ephrin-B1 in the adult hippocampus, suggesting impaired maturation of these newly formed and potentially silent synapses or increased excitatory drive on the inhibitory neurons resulting in the overall decreased postsynaptic firing. 

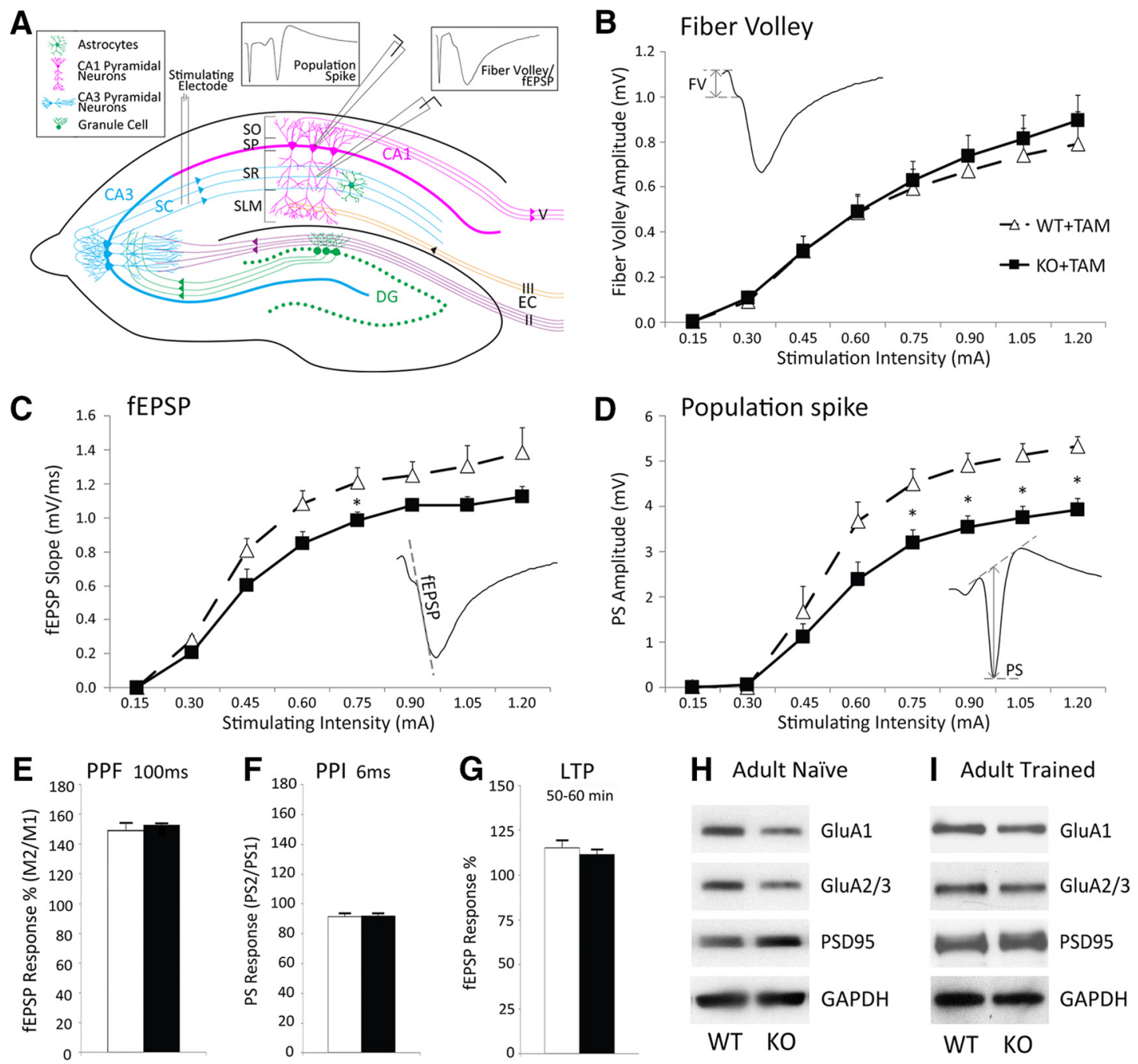

J Adult Naïve
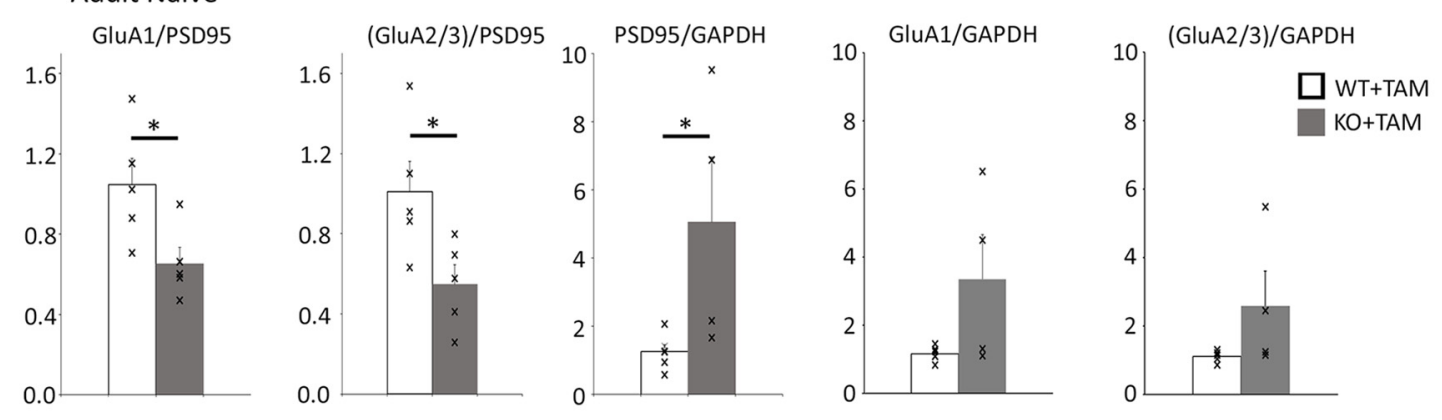

Adult Trained
GluA1/PSD95
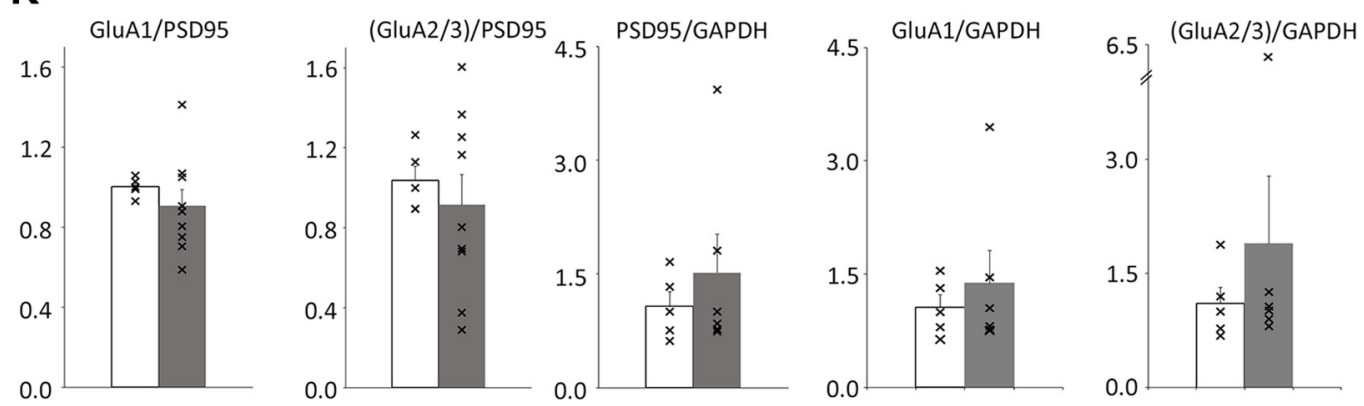

Figure 3. Functional synaptic changes in CA1 hippocampal neurons of astrocyte-specific ephrin-B1 KO mice. $\boldsymbol{A}$, Schematics of hippocampal circuit showing the placement of electrodes for extracellular stimulation and field potential recordings with the examples of stereotypical responses after stimulation. $\boldsymbol{B}-\mathbf{D}, \mathrm{I} / \mathbf{0}$ curves were generated by plotting the amplitude of $\mathrm{FV}$ presynaptic responses $(\boldsymbol{B})$, fEPSP slope for postsynaptic dendritic responses $(\boldsymbol{C})$, and PS amplitude for postsynaptic neuronal responses $(\boldsymbol{D})$ of CA1 hippocampal neurons (Figure legend continues.) 
Astrocyte-specific deletion of ephrin-B1 in the adult hippocampus triggers formation of synapses with reduced levels of AMPA receptors

To assess synapse maturation, we determined the levels of synaptic AMPAR subunits GluA1 and GluA2/3 in the adult hippocampus of WT and $\mathrm{KO}$ mice. Crude synaptosomes were isolated from P90-P120 hippocampi of WT and KO mice following tamoxifen treatment and analyzed with immunoblotting (Fig. $3 H$ ). A significant increase in synaptic PSD95 levels was observed in $\mathrm{KO}$ compared with WT group (Fig. $3 J$ ), most likely due to an overall increase in excitatory synapse number (Fig. 2O). Although GluA1 and GluA2/3 levels were not different between the groups (Fig. $3 J$ ), we observed a significant decrease in the AMPAR/PSD95 ratio by assessing synaptic levels of AMPAR subunits GluA1 and GluA2/3 (Fig. 3J). This is consistent with the increase in the proportion of immature dendritic spines with small heads (Fig. $2 F$ ) observed in KO mice compared with WT mice, suggesting that some of the PSD95-positive synaptic sites may be potentially silent and are lacking AMPARs.

\section{Contextual memory is enhanced in astro-ephrin-B1 KO mice following fear conditioning}

As immature synapses are preferential sites for spine enlargement (Matsuzaki et al., 2004), we next tested whether additional train-

$\leftarrow$

(Figure legend continued.) as a function of the stimulation intensity of Schaffer collaterals in acute hippocampal slices from WT + TAM and KO+TAM adult mice. $\boldsymbol{B}$, There were no significant differences in presynaptic responses between the groups $(n=6-8$ mice; genotype $X$ stimulation intensity interaction: $F_{(1,112)}=1.072, p=0.3027$, two-way ANOVA followed by Bonferroni post-test). C, Overall, fEPSP slope was not significantly different in KO+TAM animals compared with WT + TAM group with a trend toward lower fEPSPs in K0 group $(n=6-8$ mice; genotype $\times$ stimulation intensity interaction: $F_{(18,153)}=1.057, p=0.4007$, two-way ANOVA followed by Bonferroni post-test). $\boldsymbol{D}$, Population spike amplitude was significantly reduced in KO + TAM mice compared with WT + TAM mice $(n=6-8$ mice; genotype $\times$ stimulation intensity interaction: $F_{(9,99)}=4.882, p<0.001$, two-way ANOVA followed by Bonferroni post-test; ${ }^{*} p<0.05$ ). $\boldsymbol{E}$, Graph shows that fEPSP responses were facilitated following the second stimulus compared with first stimulus at $100 \mathrm{~ms}$ stimulation interval in both WT + TAM and K0 + TAM mice with no differences in PPF between the groups. Graphs show mean values and error bars represent SEM ( $n=6-8$ mice, Student's $t$ test). $\boldsymbol{F}$, Graph shows that the changes in PS amplitude between first and second stimulus at 6 ms stimulation interval were not significantly different between WT + TAM and KO + TAM groups. Graphs show mean values and error bars represent SEM ( $n=6-8$ mice, Student's $t$ test). $G$, Graph shows that the potentiation was maintained $50-60$ min after LTP induction in both WT + TAM and KO + TAM groups with no differences between the groups. Graph shows mean values and error bars represent SEM ( $n=6-8$ mice, Student's $t$ test). $\boldsymbol{H}, \boldsymbol{I}$, Western blots show levels of AMPAR subunits (GluA1 and GluA2/3), PSD95 and GAPDH in synaptosomes isolated from the hippocampus of $(\boldsymbol{H})$ naive and $(\boldsymbol{I})$ trained WT and KO mice following contextual fear conditioning. $\boldsymbol{J}, \boldsymbol{K}$, Graphs show ratios of synaptic GluA1 or GluA2/3 levels to PSD95 levels and PSD95 to GAPDH ratios in synaptosomes isolated from the hippocampus of $(\boldsymbol{J})$ naive and $(\boldsymbol{K})$ trained WT and KO mice following contextual fear conditioning. Graphs show individual values (marked by $\mathrm{x}$ ), mean values and error bars represent SEM $\left(n=5\right.$ mice per group, $t$ test, $\left.{ }^{*} p<0.05\right)$. J, There was a significant increase in synaptic PSD95 levels in naive K0 compared with naive WT (WT+ TAM: $1.252 \pm 0.204$ vs K0 + TAM: $\left.5.058 \pm 1.895, t_{(8)}=2.505, p=0.0366\right)$. GluA1 and GluA2/3 levels were not significantly different between the groups (GluA1 WT + TAM: $1.168 \pm$ 0.087 vs KO+TAM: $3.358 \pm 1.309, t_{(8)}=2.104, p=0.0685 ;$ GluA2/3 WT+TAM: $1.118 \pm$ 0.075 vs KO + TAM: $\left.2.589 \pm 1.010, t_{(7)}=1.65, p=0.143\right)$. However, there was a significant decrease in AMPAR/PSD95 ratio for synaptic GluA1 (WT+TAM: $1.04 \pm 0.13$ vs K0+TAM: $0.65 \pm 0.079, t_{(8)}=2.564, p=0.0335, t$ test) and GluA2/3 subunits (WT + TAM: $1.01 \pm 0.15$ vs KO+ TAM: $\left.0.54 \pm 0.09, t_{(8)}=2.687, p=0.0276\right) . K$, Following training, PSD95 levels were similar between K0 + TAM and WT + TAM (WT + TAM: $1.073 \pm 0.191$ vs KO: $1.517 \pm 0.509$, $t_{(9)}=0.7545, p=0.4698$ ). There were also similar levels of AMPAR (GluA1 WT+TAM: $1.059 \pm 0.167$ vs K0+TAM: $1.380 \pm 0.428, t_{(9)}=0.647, p=0.534, t$ test; GluA2/3 WT+TAM: $1.105 \pm 0.213$ vs K0+TAM: $1.890 \pm 0.885, t_{(9)}=0.788, p=0.451, t$ test $)$ and AMPAR/PSD95 ratios (GluA1:WT+ TAM: $1.003 \pm 0.007$ vs K0 + TAM: $0.918 \pm 0.091, t_{(12)}=$ $0.6931 p=0.505, t$ test; GluA2/3: WT+TAM: $1.032 \pm 0.062$ vs K0+TAM: $0.799 \pm 0.106$; $t_{(12)}=1.537, p=0.152, t$ test). ing would trigger synapse maturation and enhance contextual hippocampal-dependent learning in $\mathrm{KO}$ mice using a fear conditioning test. WT, WT+ TAM, and $\mathrm{KO}+\mathrm{TAM}$ mice were trained to associate an electric shock with a tone in Context A. Their ability to recall the context and tone was then tested by measuring the amount of time freezing in Context A without tone (context recall) and in Context $B$ with a tone (tone recall) respectively (Fig. $4 A-G)$. Hippocampal tissues were collected following tone recall and synaptosomes were assessed for AMPAR and PSD95 levels (Fig. 3I). We observed similar synaptic levels of PSD95 in $\mathrm{KO}+\mathrm{TAM}$ and $\mathrm{WT}+\mathrm{TAM}$ groups (Fig. $3 \mathrm{~K}$ ), most likely due to increased synaptic levels of PSD95 in WT mice following training. In contrast to the reduced AMPAR/PSD95 ratio in naive $\mathrm{KO}$ mice compared with WT (Fig. 3J), we found similar AMPAR/ PSD95 ratio in the hippocampus of trained WT and KO mice by assessing the synaptic levels of AMPAR subunits GluA1 and GluA2/3 (Fig. 3K), suggesting possible recruitment of AMPAR to PSD95-positive sites in the KO group. In addition, a significant $30 \%$ increase in freezing during contextual recall was observed in $\mathrm{KO}+\mathrm{TAM}$ mice compared with WT and WT+ TAM mice (Fig. $4 E) . \mathrm{KO}+\mathrm{TAM}$ mice also showed a significant increase in contextual memory renewal following fear memory extinction and reactivation (Fig. $4 H-K$ ).

Our results suggest that the formation of immature synapses following astrocyte-specific loss of ephrin-B1 in adult mice may enhance long-term contextual memory through the recruitment of AMPARs to synaptic sites elicited by training. Although the role of astrocytic ephrin-B1 in inhibitory neurons is not completely clear, increased excitatory drive onto inhibitory neurons may also contribute to the enhanced contextual memory recall and renewal in $\mathrm{KO}$ mice.

\section{Astrocytes overexpressing ephrin-B1 induce the loss of excitatory synapses in primary hippocampal neurons}

Deletion of ephrin-B1 in adult astrocytes promoted synapse formation in the hippocampus, suggesting that astrocytic ephrin-B1 is a negative regulator of synaptogenesis. To determine whether astrocytic ephrin-B1 inhibits synapse formation, we examined the effects of ephrin-B1 overexpression in astrocytes on synapses in primary hippocampal neuronal cultures. GFP-expressing astrocytes lacking or overexpressing ephrin-B1 (green) were added to 13 DIV hippocampal cultures containing MAP2-positive neurons (Fig. $5 A-C$, red). Ephrin-B1 immunoreactivity was detected in WT astrocytes (Fig. $5 C$, arrowhead), astrocytes overexpressing ephrin-B1 (Fig. 5B), but not ephrin-B1 KO astrocytes (Fig. 5C, arrow). We next measured synapsin-positive immunoreactive puncta associated with GFP-labeled control (GFP), ephrin-B1 $\mathrm{KO}\left(\mathrm{GFP}+\mathrm{Cre}^{\text {GFAP }}\right.$ ephrin-B1 $\left.{ }^{\text {flox }}\right)$, and ephrin-B1 overexpressing $(\mathrm{GFP}+$ ephrin-B1) astrocytes in these mixed astrocyte-neuronal cultures $24 \mathrm{~h}$ after the addition of astrocytes (Fig. $5 A, D$ ). To our surprise we found an increase in the number of synapsin-positive boutons associated with both ephrin-B1 overexpressing and ephrin-B1 KO astrocytes compared with controls (Fig. 5E). However, a significant portion of the synapsin-positive boutons detected within ephrin-B1 overexpressing astrocytes was not colocalized with postsynaptic protein PSD95 (Fig. $5 D, F$ ). In particular, higher number of synapsin-positive puncta lacking PSD95 was observed in the cell body of ephrin-B1 OE astrocytes (Fig. 5D, arrowhead) compared with control or ephrin-B1 KO astrocytes (Fig. 5D). In contrast, the colocalization of PSD95 and synapsin puncta was significantly higher near ephrin-B1 KO astrocytes compared with ephrin-B1 overexpressing astrocytes (Fig. $5 F$ ) showing an overall decrease in the number of synapses 


\section{A Auditory fear conditioning}

day $110 \mathrm{~min}$

WT $\square$ WT+TAM $\quad$ KO+TAM


Figure 4. Performance of astro-ephrin-B1 K0 mice is improved in contextual fear conditioning test. $A$, Schematic depiction of fear conditioning test. Mice were habituated to contexts A and B for $10 \mathrm{~min}$ on day 1 . On day 2 mice were placed in Context $A$ and received 5 random $0.7 \mathrm{~mA}$ foot shocks for $2 \mathrm{~s}$ after a $30 \mathrm{~s}$ tone at $70 \mathrm{~Hz}$, training the mice to associate the tone with the foot shock. On day 3 mice were placed in Context A for $5 \mathrm{~min}, 1 \mathrm{~h}$ later mice were placed in Context $B$ for 6 min and exposed to a $70 \mathrm{~dB}$ tone for the last 3 min. $\boldsymbol{B}-\boldsymbol{G}$, Graphs show the percentage of time that mice freeze during each trial, including Context A habituation $(\boldsymbol{B})$, Context B habituation $(\boldsymbol{C})$, Context A training $(\boldsymbol{D})$, Context A recall $(\boldsymbol{E})$, Context B without $(\boldsymbol{F})$, and with tone $(\boldsymbol{G})$. K0+TAM mice show higher freezing than WT and WT + TAM mice during Context A recall (E). Graphs show mean values and error bars represent SEM $(n=20-21$ mice per group, two-way ANOVA followed by Bonferroni multiple-comparison post-test; $\left.F_{(4,146)}=3.601^{*} p<0.05\right)$. $\boldsymbol{H}-\boldsymbol{K}$, Graphs show the percentage of time that mice freeze during extinction in Context $\mathrm{A}(\boldsymbol{H})$, Context $\mathrm{B}$ recall without tone $(\boldsymbol{I})$, memory reactivation in Context $B$ with a tone $(\boldsymbol{J})$, and memory renewal in Context $A(K)$. KO + TAM mice show higher freezing than WT + TAM mice during memory renewal in Context A. Graphs show mean values and error bars represent SEM ( $n=5$ mice per group, $t$ test; $\left.{ }^{*} p<0.05 t_{(7)}=2.534\right)$.

containing both presynaptic and postsynaptic sites near astrocytes overexpressing ephrin-B1.

Our results suggest that astrocytes overexpressing ephrin-B1 may disrupt synapses by removal of EphB-containing presynaptic boutons away from the postsynaptic sites.

Reverse signaling through ephrin-B1 regulates astrocyte engulfment of synaptosomes containing EphB receptors To determine whether ephrin-B1-EphB receptor interactions are responsible for astrocyte-mediated engulfment of presynaptic boutons, we tested the ability of astrocytes expressing ephrin-B1 to engulf the synaptosomes with or without EphB receptors. Astrocyte cultures were incubated for 2 or $4 \mathrm{~h}$ with DiI-labeled crude synaptosomes isolated from WT or EphB1/2/3 KO mouse hippocampi (Fig. 6A-D). Enrichment of synaptic proteins PSD95 and synapsin-1 in synaptosomes was confirmed by immunoblotting (Fig. 6E). Immunostaining showed clustering of astrocytic ephrin-B1 around WT synaptosomes suggesting possible interactions between astrocytic ephrin-B1 and neuronal EphB receptors in synaptosomes (Fig. 6B). Astrocyte-expressing ephrin-B1 contained significantly more WT synaptosomes than synaptosomes lacking EphB1/2/3 receptors $2 \mathrm{~h}$ after the addition of synaptosomes (Fig. 6C). In addition, loss-of-function mutations in ephrin-B1 intracellular domain (Fig. $6 F$ ) also affected astrocyte engulfment of synaptosomes (Fig. 6C,D). Although there were no differences in the expression levels of ephrin-B1 or its loss-of-function mutants ephrin-B1Y294F, ephrin-B1Y310F, and ephrin-B1Y294F/Y310F in transfected astrocytes (Fig. 6G), we observed a significant $69 \%$ decrease in synaptosome engulfment by astrocytes expressing ephrin-B1Y294F/Y310F mutant compared with astrocytes expressing ephrin-B1 (Fig. 6C).

Our results suggest that astrocytic ephrin-B1 most likely regulates synapse numbers by pruning immature synapses through astrocyte-dependent trans-endocytosis.

Contextual memory is impaired in adult mice following overexpression of ephrin-B1 in hippocampal astrocytes If astrocytic ephrin-B1 acts as a negative regulator of new synapse formation then we expect that overexpression of ephrin-B1 in adult hippocampal astrocytes would affect new synapse formation during contextual learning. To induce expression of ephrin-B1 and/or tdTomato in astrocytes, mouse hippocampi were bilaterally injected with AAV virus containing $G f a A B C 1 D$. ephrin-B1.SV40 and/or GfaABC1D.tdTomato.SV40. Viral microinjections targeted dorsal CA1 hippocampus of P60-P70 mice allowing for expression of tdTomato or tdTomato + ephrin-B1 in CA1 hippocampal astrocytes 2 weeks later. Transfected astrocytes were identified by tdTomato fluorescence and ephrin-B1 overexpression was confirmed by immunostaining (Fig. 7A,B). Astrocytic ephrin-B1 levels were significantly increased in animals injected with AAV-ephrinB1 +AAV-tdTomato compared with AAV-tdTomato only injected mice (Fig. 7C). Overexpression of astrocytic ephrin-B1 lead to a $25 \%$ decrease in the number of vGlut1-positive puncta, but not GAD65 puncta, in SR area of 

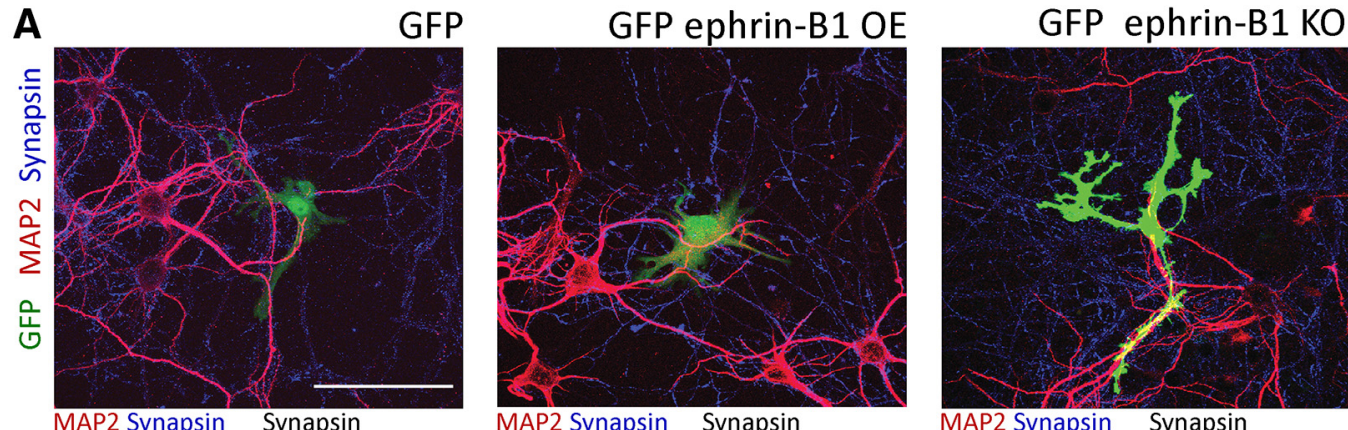

는
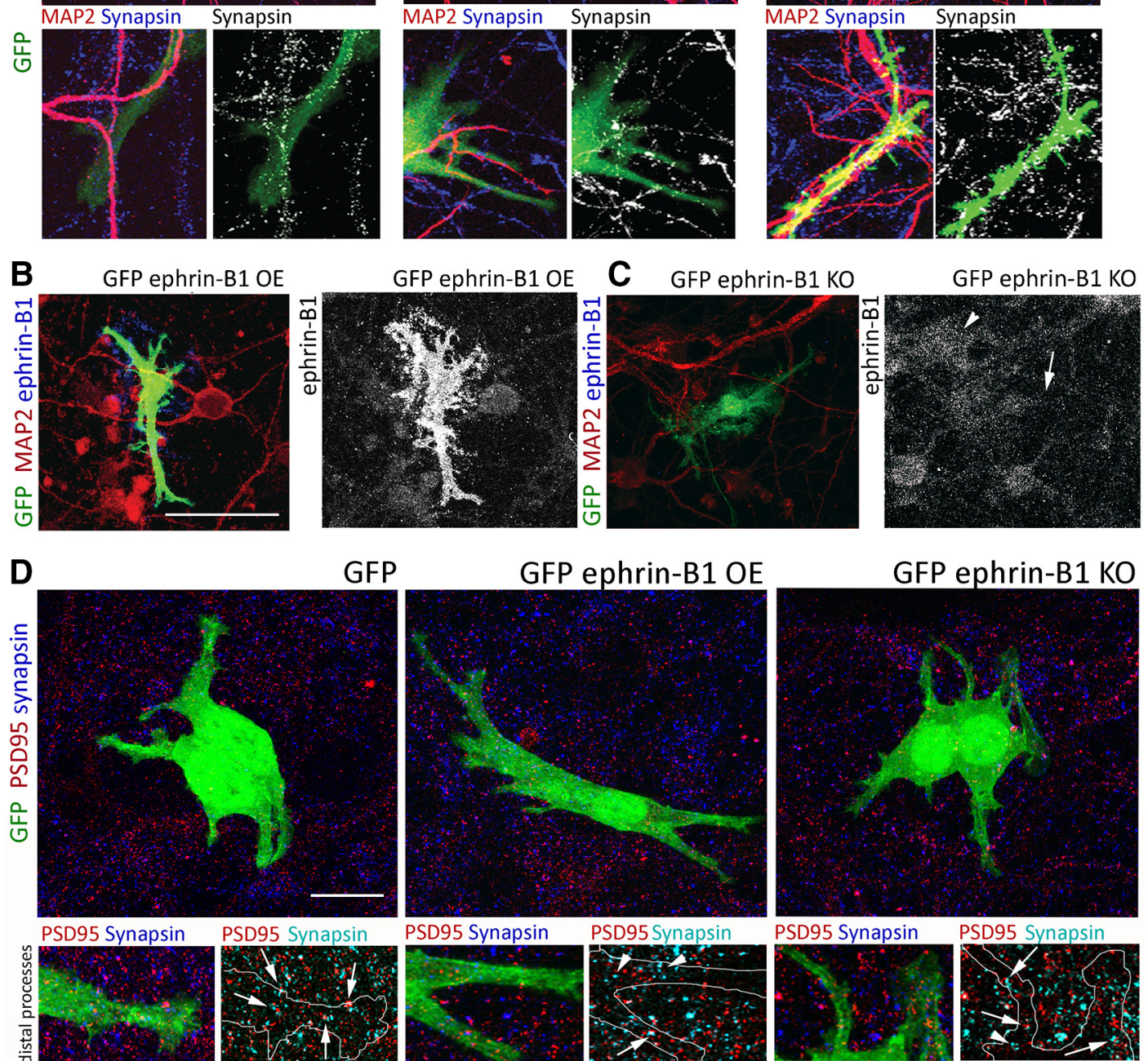

PSD95 Synapsin
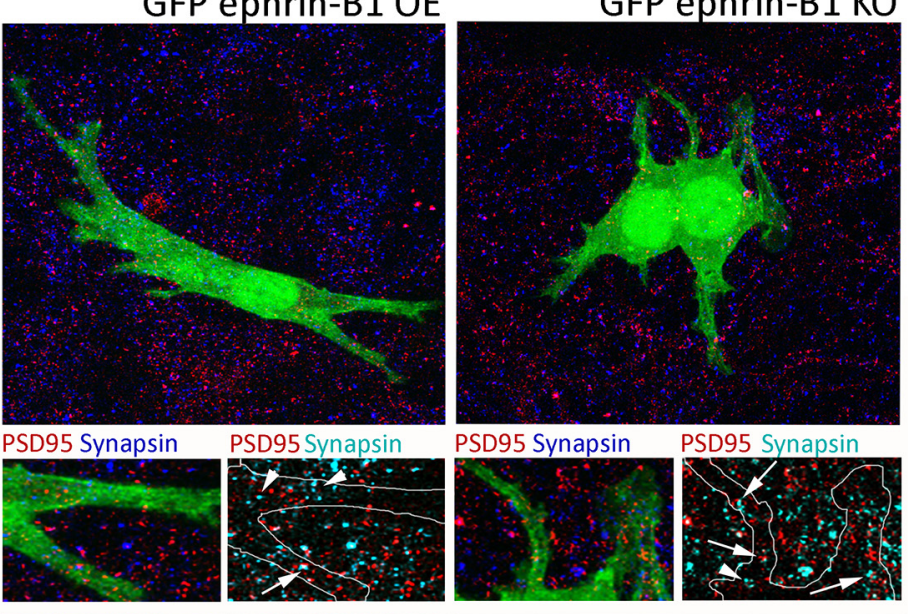

PSD95 Synapsin
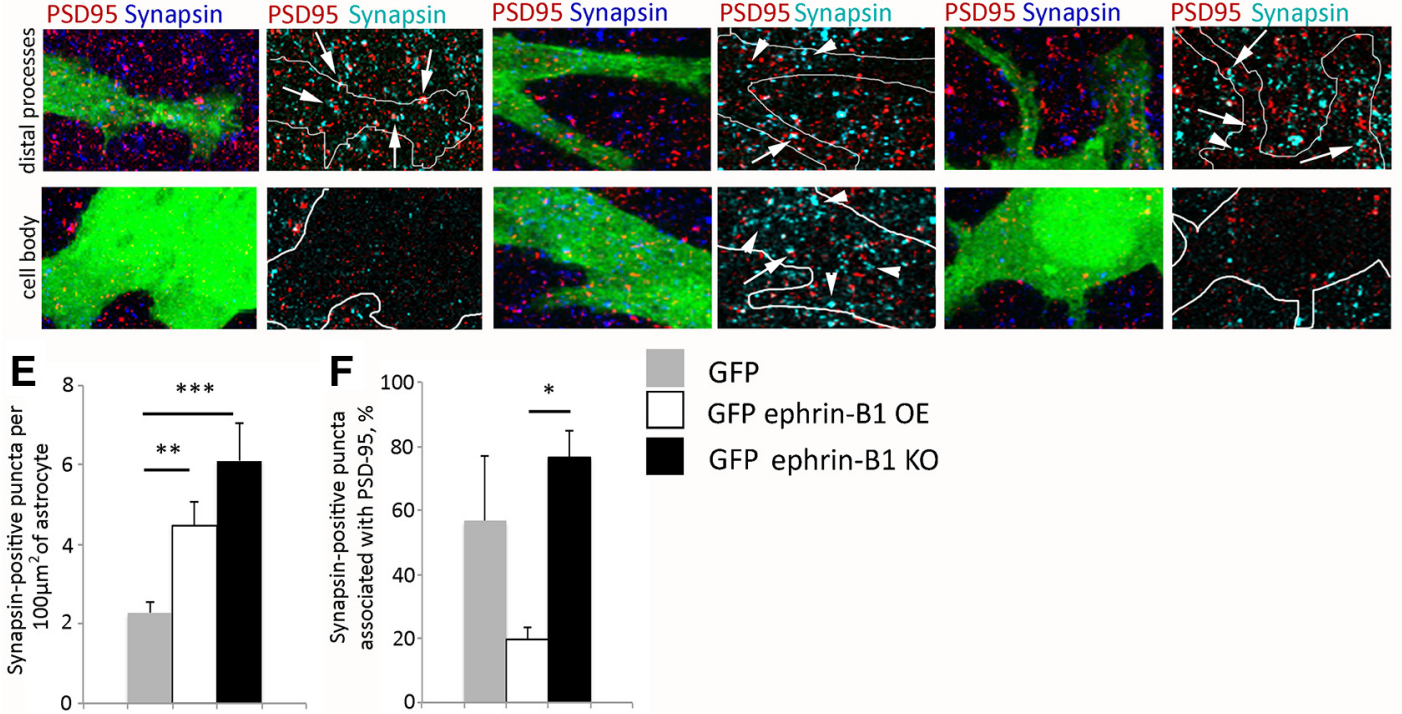

GFP

GFP ephrin-B1 OE

GFP ephrin-B1 KO

Figure 5. Astrocytic ephrin-B1 alters synaptogenesis in primary hippocampal cultures. $\boldsymbol{A}-\boldsymbol{D}$, Confocal images show astrocytes expressing GFP, GFP plus ephrin-B1 (ephrin-B1 0E), or GFP plus Cre ${ }^{G F A P}$ ephrin-B1 ${ }^{\text {flox }}$ (ephrin-B1 KO) in mixed glial/neuronal cultures. Hippocampal neuron cultures were prepared from E15 pups. Primary astrocytes were isolated from WT or Cre ${ }^{\text {GFAP }}$ ephrin-B ${ }^{\text {flox }}$ mouse hippocampi at P0-P3, cultured in DMEM with 10\% FCS for $14 \mathrm{~d}$, transfected with pEGFP (GFP) or pEGFP+ pcDNA-ephrin-B1 (GFP+ephrin-B1) and added (Figure legend continues.) 
CA1 hippocampus of astro-ephrin-B1 OE group compared with control group (Fig. $7 D, E$ ). Overexpression of ephrin-B1 also lead to a $34 \%$ decrease in dendritic spine density (Fig. $7 F, G$ ), and a $28 \%$ increase in spine volume (Fig. $7 I$ ) without the changes in spine length (Fig. $7 \mathrm{H}$ ), supporting our assumption that astrocytic ephrin-B1 promotes removal of immature spines.

To determine whether overexpression $(\mathrm{OE})$ of ephrin-B1 in adult hippocampal astrocytes also affected hippocampal-dependent learning, we examined contextual memory acquisition and recall using a fear conditioning paradigm. Fourteen days postinjection, mice were trained to associate an electric shock with a tone in Context A (Fig. 7J-O). Their ability to recall context and tone association was then tested $24 \mathrm{~h}$ after the training by measuring mouse freezing time in Context A without tone (context recall; Fig. $7 M$ ) and in Context B with a tone (tone recall), respectively (Fig. 7O). We found no differences between control and astro-ephrin-B1 OE groups during the training (Fig. $7 \mathrm{~L}$ ), but a significant reduction in freezing was observed during contextual recall in astro-ephrin-B1 OE mice compared with control mice (Fig. $7 M$ ). It appears that freezing time of astro-ephrin-B1 $\mathrm{OE}$ mice during contextual recall $24 \mathrm{~h}$ after training $(22.23 \pm$ 5.12) was not significantly different from their freezing time during initial habituation to the Context A before the training $(14.85 \pm 2.11)$. In contrast, control mice expressing tdTomato retained fear memory of Context A and were freezing more $24 \mathrm{~h}$ after training $(35.14 \pm 2.11)$ than during habituation $(16.68 \pm$ $0.28, t_{(8)}=8.673, p=0.0004, t$ test $)$.

These findings suggest that overexpression of ephrin-B1 in hippocampal astrocytes impairs new memory formation, most likely by reducing the number of excitatory synapses available for new memories. Alternatively, decreased excitatory drive onto parvalbumin (PV)-positive inhibitory interneurons may also affect contextual memory recall by reducing inhibitory activity in the CA1 hippocampus.

\section{Discussion}

The studies presented here demonstrate the potential role of astrocytes in maintaining hippocampal circuits in the adult mouse brain via astro-ephrin-B1, acting as a regulator of synaptic homeostasis in the adult hippocampus. It is thought that plastic nature of hippocampal circuits underlies life-long learning and memory formation, and as such, ongoing synapse pruning and restructuring play an important role in maintaining synaptic homeostasis in the adult hippocampus (Maletic-Savatic et al., 1999; Spacek and Harris, 2004; Stevens and Williams, 2007; Schafer and Stevens, 2010; Paolicelli et al., 2011). Synapse numbers can be maintained by regulating new synapse formation or by removing

\section{$\leftarrow$}

(Figure legend continued.) to $13 \mathrm{DIV}$ hippocampal neurons for $24 \mathrm{~h}$. Mixed cultures were fixed and immunolabeled against MAP2 ( $\boldsymbol{A}-\boldsymbol{C}$, red), synapsin1 ( $\boldsymbol{A}$ and $\boldsymbol{D}$, blue), PSD95 ( $\boldsymbol{D}$, red) or ephrinB1 ( $\boldsymbol{B}, \boldsymbol{C}$, blue). Scale bars: $\boldsymbol{A}-\boldsymbol{C}, 50 \mu \mathrm{m} ; \boldsymbol{D}, 15 \mu \mathrm{m}$. $\boldsymbol{C}$, Lower ephrin-B1 immunoreactivity was observed in GFP-expressing ephrin-B1 K0 astrocyte (arrow) compared with WT astrocyte (arrowhead). D, Colocalized PSD95/synapsin puncta was observed near distal astrocytic processes of control GFP, ephrin-B1 0E and ephrin-B1 K0 astrocytes (arrow). In contrast a higher number of synapsin-positive puncta lacking PSD95 was seen in the cell body of ephrin-B1 OE astrocytes (arrowhead), but not control GFP and ephrin-B1 K0 astrocytes. E, F, Graphs show the number of synapsin-positive presynaptic puncta per $100 \mu \mathrm{m}^{2}$ of astrocyte $(\boldsymbol{E} ; n=10-20$ astrocytes per group, control: $2.28 \pm 0.26$, ephrin-B1 0E: $4.47 \pm 0.58$, ephrin-B1 K0: $6.10 \pm$ $0.99, F_{(2,34)}=9.758, p=0.0004$, one-way ANOVA with Tukey's post hoc; ${ }^{*} p<0.05$, ${ }^{* *} p<$ $\left.0.01,{ }^{* * *} p<0.001\right)$ and percentage of synapsin-positive puncta colocalized with PSD95 $(F$; $n=10-20$ astrocytes per group, ephrin-B1 OE: $19.67 \pm 6.32$, ephrin-B1 K0: $76.44 \pm 9.15$, $F_{(2,34)}=3.641, p=0.0369$, one-way ANOVA with Tukey's post hoc; ${ }^{*} p<0.05,{ }^{* *} p<0.01$, $\left.{ }^{* * *} p<0.001\right)$. Graphs show mean values and error bars represent SEM. weak, potentially silent, synaptic connections creating an opportunity for new connections to form. Our findings are consistent with the role of astro-ephrin-B1 as a negative regulator of synapse formation in the adult hippocampus, as astrocyte-specific ablation of ephrin-B1 in adult mice triggers an increase in the density of glutamatergic synapses and dendritic spines. Although, these effects appear to be specific to excitatory synapses, as no changes were observed in the number of inhibitory GAD65-positive sites in CA1 hippocampus following astrocyte-specific deletion of ephrin-B1, increased excitatory drive onto PV-positive interneurons may also contribute to enhanced contextual memory recall as the activation of PV interneurons was linked to contextual fear memory (Donato et al., 2013, 2015). This increase in excitatory synapses was observed in SR but not SLM area of CA1 hippocampus. The layer-specific changes are noteworthy considering the role of postsynaptic ephrin-B in CA3-CA1 excitatory connections (Grunwald et al., 2004), where EphB1 and EphB2 receptors are expressed on presynaptic CA3 fibers that contact CA1 dendrites expressing ephrin-B ligands (Liebl et al., 2003). Therefore, astro-ephrin-B1 may restrict the formation of new CA3-CA1 connections by interfering with the interactions between presynaptic EphB receptors and dendritic ephrin-B, whereas reduced expression of ephrin-B1 in astrocytes may promote new synapse formation. It is possible that presynaptic input received from entorhinal cortex by CA1 neurons in SLM area is not sensitive to the changes in ephrin-B1 expression in hippocampal astrocytes due to low expression of EphB1 and EphB2 receptors (Liebl et al., 2003; Chenaux and Henkemeyer, 2011).

In addition to its presynaptic role in CA3-CA1 synapses, EphB2 receptor is also expressed postsynaptically on the dendrites of CA1 neurons and has been implicated in synapse development both in vitro and in vivo (Ethell et al., 2001; Henderson et al., 2001; Takasu et al., 2002; Henkemeyer et al., 2003; Liebl et al., 2003). Postsynaptic EphB receptors are implicated in both clustering and recruitment of NMDARs and AMPARs to the postsynaptic sites (Dalva et al., 2000; Takasu et al., 2002; Kayser et al., 2006; Nolt et al., 2011; Hussain et al., 2015). Therefore, it is possible that astro-ephrin-B1 may also influence postsynaptic functions by disrupting postsynaptic EphB signaling and we would expect an increase in synaptic strength in the adult hippocampus following the deletion of ephrin-B1 from astrocytes. To our surprise, despite an increase in synapse numbers, we observed reduced postsynaptic firing responses in the CA1 hippocampus of astrocyte-specific ephrin-B1 KO mice. Deletion of astroephrin-B1 in adult hippocampus had no effect on presynaptic fiber volley responses, but significantly reduced population spike amplitude in CA1 neurons following the stimulation of Schaffer collaterals. The postsynaptic nature of the observed changes is further supported by the fact that PPF is not affected by the deletion of astro-ephrin-B1, suggesting that the presynaptic release of glutamate is normal, whereas the population spike amplitude, or the postsynaptic neural firing strength, is reduced in astroephrin-B1 KO compared with WT mice.

Synapse formation does not always correlate with an increase in synaptic strength, as newly formed synapses are often associated with silent postsynaptic spines that are usually smaller and are characterized by the presence of NMDA but absence of AMPA receptors (Isaac et al., 1995; Durand et al., 1996). The abundance of immature silent synapses may explain the reduced postsynaptic responses observed in astro-ephrin-B1 KO mice despite the increase in the total number of synapses. Indeed, deletion of astro-ephrin-B1 resulted in a nearly twofold increase in the number of immature dendritic spines with small heads, over- 
A

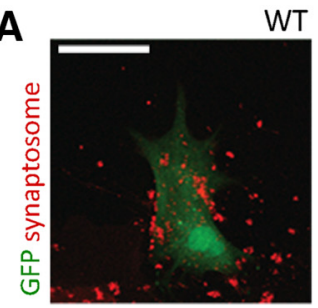

B
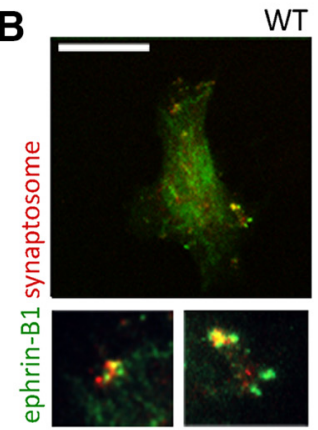

c

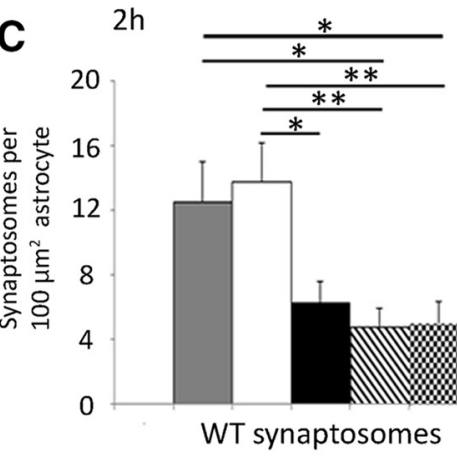

ephrin-B1



ephrin-B1
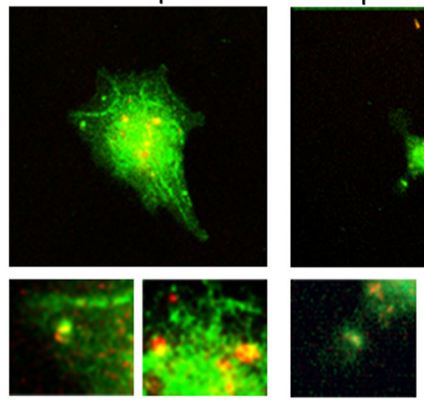

Control

$\square$ ephrin-B1

ephrin-B1 Y294F

V/, ephrin-B1 Y310F

\%ephrin-B1 Y294/310F

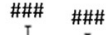

EphB1/2/3 KO synaptosomes

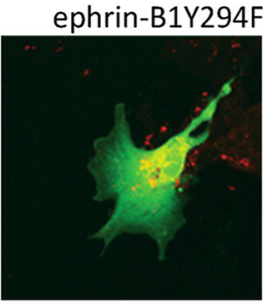

ephrin-B1Y294F
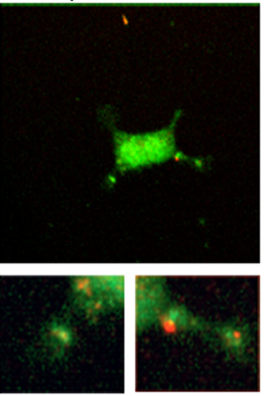

ephrin-B1Y310F ephrin-B1Y294/310F

ephrin-B1Y310F
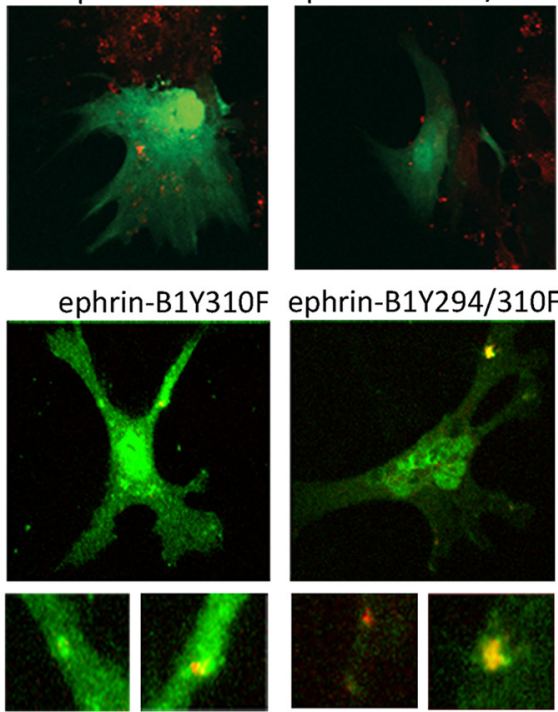

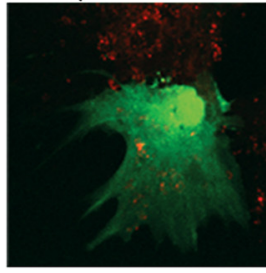

ephrin-B1Y294/310F

D $\quad 4 \mathrm{~h}$

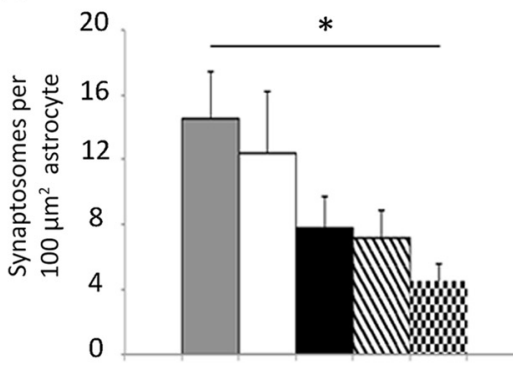

WT synaptosomes
E

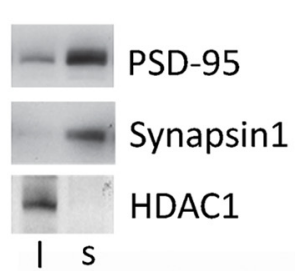

$\mathbf{F}$ ephrin-B1

RBD

TD
YXXX

\begin{tabular}{c} 
ephrin-B1Y294F \\
RBD \\
\hline
\end{tabular}

$\mathrm{F}=\mathrm{YCPH}(294)$

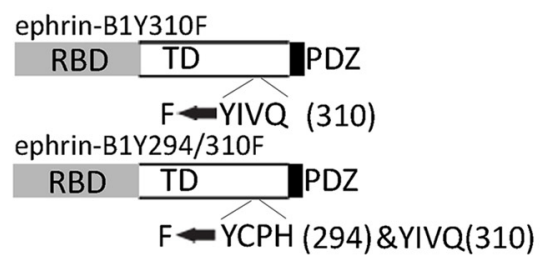

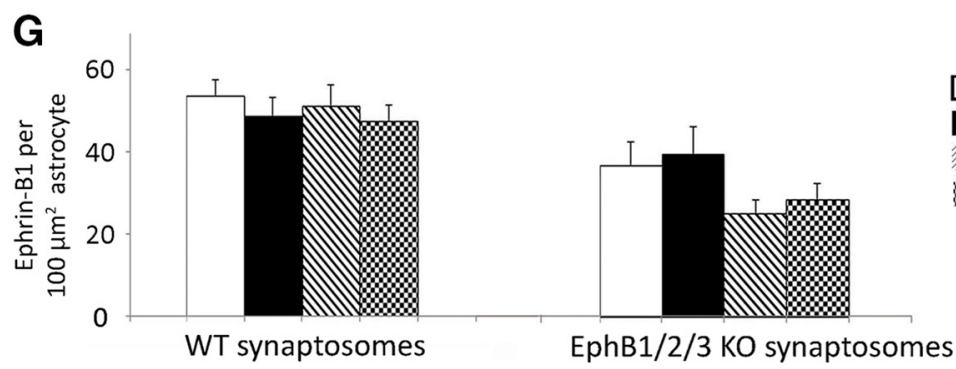

Figure 6. Ephrin-B1 reverse signaling triggers synaptosome engulfment by astrocytes. $A, B$, Confocal images of primary astrocytes expressing ephrin-B1, ephrinB1-Y294F, ephrinB1-Y310F, or ephrinB1-Y294/310F with ( $\boldsymbol{A}$ ) or without GFP (B) that were cocultured with Dil-labeled synaptosomes (red) isolated from adult mouse hippocampi for $2 \mathrm{~h}$. C, D, Graphs show the integrated density of Dil-labeled synaptosomes in astrocytes treated for $2 \mathrm{~h}(\boldsymbol{C})$ or $4 \mathrm{~h}(\boldsymbol{D})$ with WT $(\boldsymbol{C}, \boldsymbol{D})$ or EphB1,2,3 K0 synaptosomes $(\boldsymbol{C})$. Astrocytes expressing ephrin-B1 contained significantly more WT synaptosomes than synaptosomes lacking EphB1/2/3 receptors $2 \mathrm{~h}$ after addition of synaptosomes $\left(n=28-30\right.$ cells; WT: $12.99 \pm 2.40 \mathrm{vs}$ EphB1/2/3 K0: 2.11 $\pm 0.71, F_{(9,248)}=10.04, p=$ 0.000154 , one-way ANOVA, Tukey's post hoc test; ${ }^{\# \#} p<0.001$ ). Astrocytes expressing ephrin-B1Y294Y/Y310F mutant had significantly decreased synaptosome engulfment compared with astrocytes expressing ephrin-B1 (ephrin-B1Y294F/Y310F mutant astrocytes: $5.04 \pm 1.27$ vs ephrin-B1-expressing astrocytes: $12.99 \pm 2.40, F_{(9,248)}=10.04, p=0.009$, ANOVA, Tukey's post hoc test; $\left.{ }^{*} p<0.05,{ }^{* *} p<0.01\right)$. Graphs show mean values and error bars represent SEM. E, Western blots showing enrichment of synaptic proteins (PSD95 and synapsin1) and a decrease in nuclear protein HDAC1 in isolated synaptosomes. $F$, Schematics of ephrin-B1 and ephrin-B1 mutants with tyrosine (Y) to phenylalanine (F) mutations. G, Graphs show ephrin-B1 immunoreactivity per 100 $\mu \mathrm{m}^{2}$ primary hippocampal astrocytes treated with synaptosomes isolated form WT or EphB1,2,3 KO mice. Graphs show that there are no significant differences in ephrin-B1 levels in primary astrocytes transfected with pcDNA3ephrin-B1, pcDNA3ephrinB1Y294F, pcDNA3ephrinB1Y310F, or pcDNA3ephrinB1Y294/310F. Graphs show mean values and error bars represent SEM $(n=28-30$ astrocytes, one-way ANOVA followed by Tukey's post hoc test). 
A

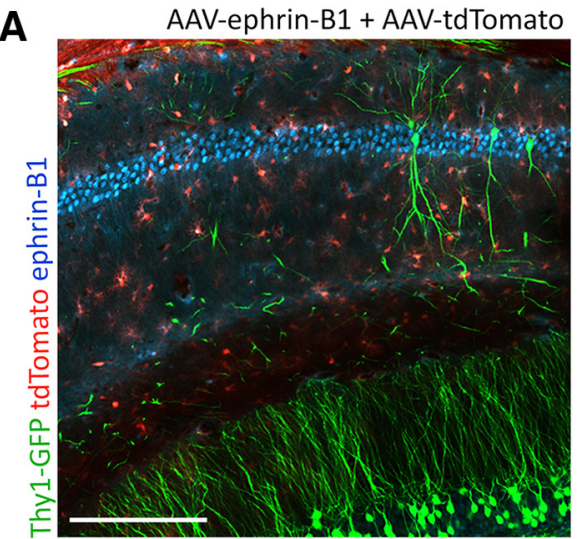

$\mathrm{F}$
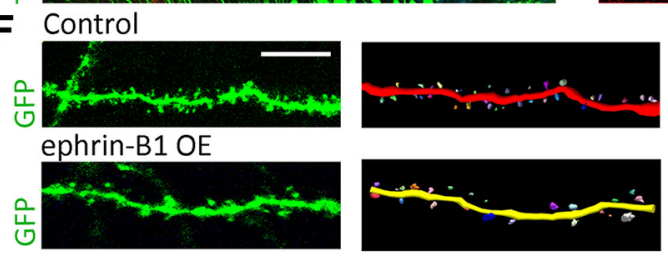

J Context A

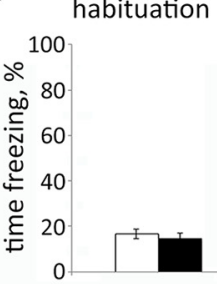

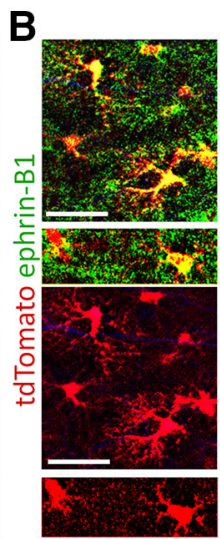
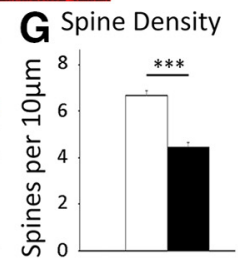

H
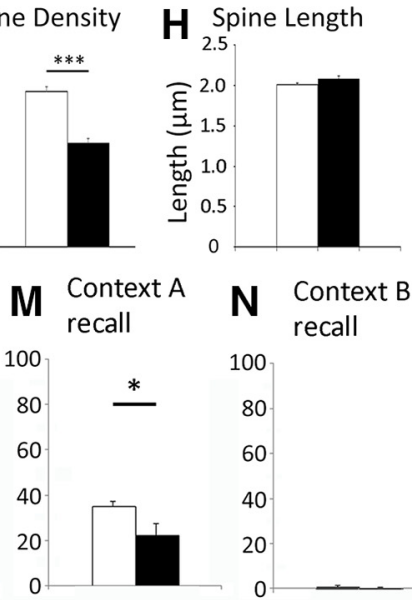

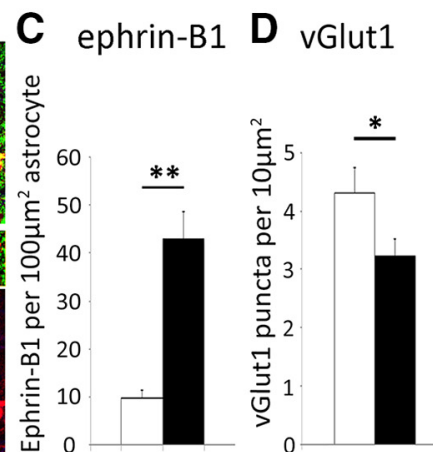

E GAD65


O Context B recall (1))

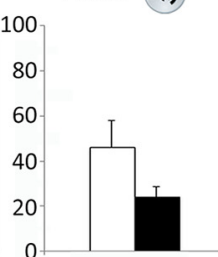

Figure 7. Contextual learning is impaired in mice overexpressing astrocytic ephrin-B1. A, Confocal images showing GFP (green), tdTomato (red) and ephrin-B1 immunoreactivity (blue) in CA1 hippocampus of Thy1-EGFP adult mice injected with AAV-GFAP-ephrinB1 + AAV-GFAP-tdTomato. Scale bar, $150 \mu \mathrm{m}$. B, Confocal images of hippocampal astrocytes expressing tdTomato (red) and ephrin-B1 (green). Scale bar, $25 \mu \mathrm{m}$. C, Graph shows ephrin-B1 immunoreactivity in astrocytes of AAV-GFAP-tdTomato (Control) or AAV-GFAP-ephrinB1 + AAV-GFAP-tdTomato (ephrin-B1 0E) hippocampus. There is a significant increase in ephrin-B1 levels in hippocampal astrocytes of ephrin-B1 OE compared with control mice. Graph shows mean values and error bars represent $S E M(n=$ 3 mice, 10 astrocytes per animal; ephrin-B1 0E: $42.930 \pm 5.663$ vs control: $9.678 \pm 1.729 ; t_{(4)}=5.616 ; p=0.0049, t$ test, $\left.{ }^{* *} p<0.01\right) . \boldsymbol{D}, \boldsymbol{E}$, Graphs show the density of vGlut1 (D) and GAD65-positive (E) puncta per $10 \mu \mathrm{m}^{2}$ of the SR area in the CA1 hippocampus of Thy1-EGFP adult mice injected with AAV-GFAP-tdTomato (Control) or AAV-GFAP-ephrinB1 + AAV-GFAP-tdTomato (ephrin-B1 0E). There is a significant 25\% decrease in vGlut1-positive puncta in the SR of ephrin-B1 0E group compared with WT group ( $n=5$ mice; control: $4.30 \pm 0.446$ vs ephrin-B1 0E: $3.22 \pm$ $0.297, t_{(58)}=2.016, p=0.0484, t$ test, $\left.{ }^{*} p<0.05\right)$. Graphs show mean values and error bars represent SEM. $\boldsymbol{F}$, Confocal images of Thy1-EGFP-expressing dendrites of CA1 neurons in control (AAV-tdTomato) or ephrin-B1 0E (AAV-ephrinB1+AAV-tdTomato) hippocampus with corresponding Neurolucida 360 rendering of the images. G-I, Graphs show analysis of dendritic spine density $(\boldsymbol{G})$, length $(\boldsymbol{H})$, or volume $(\boldsymbol{I})$ in SR area of CA1 hippocampus of control and ephrin-B1 0E group. There is a significant $34 \%$ decrease in dendritic spine density $(n=81-92$ dendrites, 3 mice per group; control: $6.675 \pm 0.192$ vs ephrin-B1 0E: $4.444 \pm 0.187, t_{(183)}=8.305, p=0.0001, t$ test, $\left.{ }^{* * *} p<0.001\right)$ and a $28 \%$ increase in spine volume $(n=81-92$ dendrites; 3 mice per group, control: $0.664 \pm 0.024$ vs ephrin-B1 0E: $0.851 \pm 0.04, t_{(171)}=3.866, p=0.0002, t$ test, $\left.{ }^{* * *} p<0.001\right)$ without changes to spine length $(n=81-92$ dendrites, 3 mice per group; control: $2.007 \pm 0.021$ vs ephrin-B1 0E: $2.080 \pm 0.033, t_{(185)}=1.785, p=0.0758, t$ test).J-O Graphs show the average mouse freezing during each trial, including Context A habituation (J), Context B habituation ( $K$ ), Context A training $(L)$, Context A recall $(M)$, Context B without $(\boldsymbol{N})$ and with tone $(\boldsymbol{O})$. Ephrin-B1 0E mice show reduced freezing compared with WT mice during Context A recall $(n=5$ mice per group, astro-ephrin-B1 0E: $22.23 \pm 5.12$ vs control: $35.14 \pm 2.11, t_{(7)}=2.534 p=0.039, t$ test, $\left.{ }^{*} p<0.05\right)$. However, freezing time of astro-ephrin-B1 0E mice during initial habituation to Context A before training and during contextual recall $24 \mathrm{~h}$ after training was not significantly different (astro-ephrin-B1 OE Context A habituation: $14.85 \pm 2.11 \mathrm{vs}$ astro-ephrin-B1 0E Context A recall: $22.23 \pm 5.12$ ). In contrast, control mice expressing tdTomato retained Context A fear memory and were freezing more $24 \mathrm{~h}$ after training than during habituation ( $n=5$ mice per group, tdTomato control Context A habituation: $16.68 \pm 0.28$ vs tdTomato control Context A recall: $35.14 \pm 2.1, t_{(8)}=8.673, p=0.0004, t$ test). Graphs show mean values and error bars represent SEM.

all reduction in the proportion of mature spines and a twofold decrease in the synaptic levels of AMPARs. Our results suggest that the loss of ephrin-B1 may lead to impaired ability of ephrin-B1 KO astrocytes to prevent an excessive formation of immature synapses in the adult hippocampus that may also compete for synaptic proteins with existing synapses. However, the decrease in evoked postsynaptic firing of pyramidal cells with unchanged presynaptic and only trending, but not statistically significant, decrease of postsynaptic fEPSPs may indicate a larger role of inhibition. Despite no changes to GAD65 puncta in SR area of CA1 hippocampus, increased excitatory input on the inhibitory neurons and potentially an increased perisomatic inhibitory drive of CA1 pyramidal neurons may result in the overall decreased postsynaptic firing (Miles et al., 1996). This inhibitory drive can be mediated by PV-positive interneurons, which are activated by CA3 pyramidal neurons (Ylinen et al., 1995; Tukker et al., 2007; Oren et al., 2010) and play an important role in strengthening contextual memory (Donato et al., 2013, 2015).

To determine whether the observed increase in the number of immature synapses and reduced postsynaptic firing responses in the CA1 hippocampus following ephrin-B1 deletion in adult astrocytes would affect hippocampal functions, we tested the ability of astro-ephrin-B1 KO mice to form new contextual memory using fear-conditioning paradigm. To our surprise astro-ephrin-B1 KO mice showed an increased contextual recall following fear-conditioning learning compared with WT mice. In addition, we observed a twofold increase in contextual memory reactivation following extinction, suggesting the formation of 
A

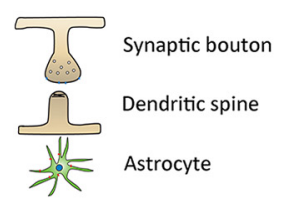

Astrocytic ephrin-B1 overexpression

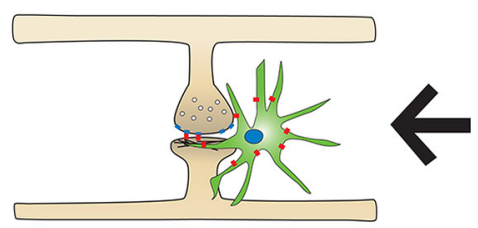

Wild Type

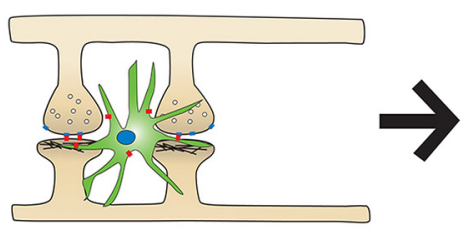

Astrocytic ephrin-B1 deletion

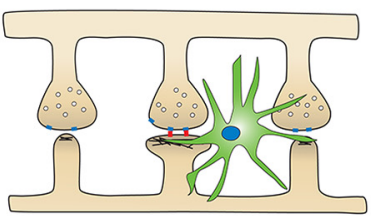

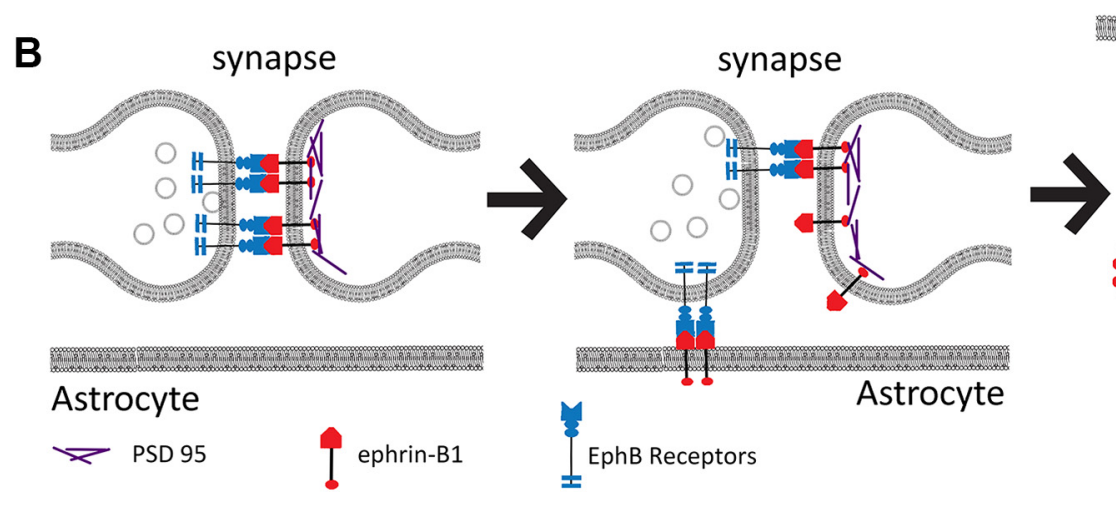

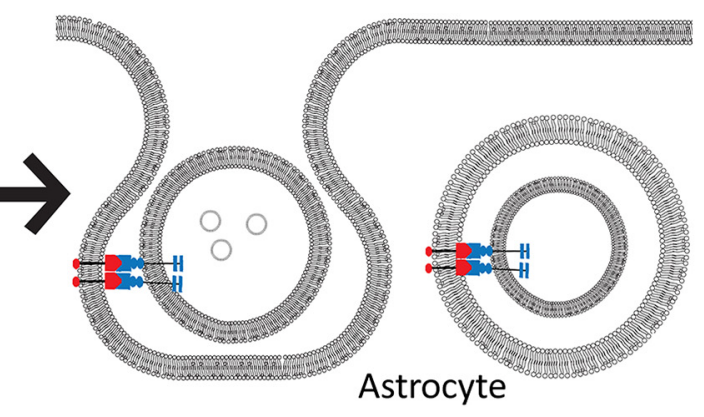

Figure 8. The role of astrocytic ephrin-B1 in synapse maintenance. $A, A$ balance between synapse formation and pruning underlies normal synapse maintenance in the adult hippocampus (middle). Astrocyte-specific deletion of ephrin-B1 results in increased formation of immature synapses and enhanced contextual memory (right). However, overexpression of ephrin-B1 in astrocytes triggers synapse loss and impairs memory (left). B, Astrocyte-mediated pruning of synapses is mediated through the interactions between astrocytic ephrin-B1 and synaptic EphB receptors, leading to the engulfment of synaptic sites that requires ephrin-B1 reverse signaling. Unoccupied synaptic EphB receptor may serve as an "eat me signal" to target synapses for removal.

long-lasting connections in astro-ephrin-B1 KO hippocampus. In contrast, contextual memory recall was impaired in mice overexpressing astro-ephrin-B1, possibly due to the removal of immature synapses by astrocytes overexpressing ephrin-B1 through their interactions with neuronal EphB receptors. Immature spines are proposed to represent potential sites of new memories (Matsuzaki et al., 2004), which can mature following persistent stimulation of synapses during fear conditioning training. Experience can modify synaptic structures through selective stabilization or removal of synapses (Lichtman and Colman, 2000; Draft and Lichtman, 2009; Holtmaat and Svoboda, 2009). Specific to the fear conditioning learning paradigm, circuit-specific insertion of newly synthesized AMPARs into spines was reported in adult hippocampal CA1 neurons $24 \mathrm{~h}$ after fear conditioning (Matsuo et al., 2008), in agreement with the role of CA1 neurons in contextual memory recall (Ji and Maren, 2008; Goshen et al., 2011) and with our studies presented here showing increased recruitment of AMPARs to hippocampal synapses following fear conditioning training. Our studies suggest that the ablation of astro-ephrin-B1 triggers excessive formation of immature and potentially AMPAR-silent synapses, resulting in reduced postsynaptic responses, but these silent synapses become mature and may be recruited to hippocampal circuits following contextual learning. In addition, an increase in the number of excitatory synapses onto PV-positive interneurons may strengthen contextual memory. Interneurons in CA3 hippocampus that express high levels of PV were shown to receive a higher excitatory input following fear conditioning (Donato et al., 2013, 2015). Direct stimulation of PV interneurons using optogenetic approach also induced high-PV network configuration. Interestingly, high-PVexpressing interneurons exhibit a higher excitatory to inhibitory input ratio compared with low-PV-expressing interneurons (Donato et al., 2015). In addition, genetically enhanced PV interneuron activity in the mouse hippocampus diminished contextual extinction without an effect on contextual memory acquisition, suggesting that the activation of PV interneurons is also critical for fear memory persistence (Çaliskan et al., 2016). Although the role of astrocytic ephrin-B1 in regulating excitatory drive onto inhibitory neurons in the hippocampus during memory formation and persistence is still not clear, future study may reveal some interesting results. It has been recently shown that the expression of ephrins in interneurons can affect the emergence and migration of interneurons and the electrophysiological properties of interneurons, such that deletion of ephrin-B result in decreased number of interneurons in both embryonic neocortex and adult hippocampus and increased excitation of cortical networks in P20-P24 mice (Talebian et al., 2017). Candidate Eph receptors in inhibitory interneurons include EphB1, EphB2, EphB3, EphB6, and EphA4 (Talebian et al., 2017). It would be interesting to look further into this relationship between ephrins and inhibitory interneurons, and whether astrocytic ephrin-B1 plays a role in these inhibitory interneurons.

Increased number of immature synapses in astro-ephrin-B1 KO hippocampus could also be a result of reduced engulfment of immature synapses by astrocytes, as primary astrocytes expressing ephrin-B1 engulf synaptosomes containing EphB receptors. Astro-ephrin-B1 may trigger the engulfment of synaptic sites through the activation of ephrin-B1 reverse signaling in astrocytes following its interaction with neuronal EphB receptor (Fig. 8). Indeed, our results indicate that ephrin-B1 reverse signaling is most likely responsible for synapse engulfment as loss-offunction mutations in ephrin-B1 intracellular domain inhibits astrocyte-mediated synaptosome engulfment. EphB receptor interactions with ephrin-B1-expressing cells usually induces clustering and activation of ephrin-B1 through its phosphorylation on tyrosines 294 and 310 (Kalo et al., 2001). Activated ephrin-B1 was reported to recruit transcription factor STAT3 through its interaction with SH2 domain (Bong et al., 2007), and adaptor proteins Grb4 and Nck to its PDZ domain (Cowan and Henkemeyer, 2001). In addition, ephrin-B1 signaling through the guanine exchange factors Tiam 1 and 2 was shown to regulate Rac1-mediated cytoskeleton remodeling that was implicated in 
EphB2/ephrin-B trans-endocytosis (Gaitanos et al., 2016). It is possible that astrocyte engulfment of EphB-expressing synapses is also mediated through ephrin-B1-induced activation of Tiams and Racl-mediated actin remodeling because we show that the deletion of EphB receptors from synapses impairs engulfment of synaptosomes by astrocytes.

In contrast to ephrin-B1 that signals through its intracellular domain, astrocyte expression of GPI-linked ephrin-A3 was previously suggested to regulate glutamate transport in the hippocampus (Carmona et al., 2009; Filosa et al., 2009). Ephrin-A3-null mice exhibited increased levels of GLT1 and GLAST, which play an important role in glutamate homeostasis and the modulation of hippocampal circuits (Carmona et al., 2009). Astrocytic ephrin-A3 can also regulate synaptic functions through its interaction with synaptic EphA4 (Murai et al., 2003; Carmona et al., 2009; Filosa et al., 2009), whereas ephrin-B1 preferentially interacts with B type Eph receptors. Indeed, the increased formation of new synapses following astrocyte-specific deletion of ephrin-B1 was not observed in ephrin-A3 KO mice (Carmona et al., 2009). In addition, no changes in basal synaptic transmission were found following the deletion of ephrin-A3 (Filosa et al., 2009), whereas astrocyte-specific loss of ephrin-B1 resulted in attenuated postsynaptic responses of CA1 neurons. Moreover, ephrin-A3 KO mice showed impaired contextual learning in a fear-conditioning test (Carmona et al., 2009), most likely due to reduction in synaptic glutamate. In contrast, we observed enhanced contextual learning following astrocytespecific deletion of ephrin-B1 and impaired contextual recall in mice overexpressing astro-ephrin-B1, suggesting a different role of ephrin-B1 in astrocytes.

In summary, our studies demonstrate that astro-ephrin-B1 is involved in the maintenance of excitatory glutamatergic synapses in the adult hippocampus, by acting as a negative regulator of synaptogenesis. Therefore, the regulation of ephrin-B1 expression in astrocytes can be targeted to manipulate new synapse formation, enhance hippocampal learning, and potentially prevent synapse loss in neurodegenerative diseases. Further understanding the role of astro-ephrin-B1 in synaptogenesis may also provide insights into astrocyte-specific mechanisms underlying abnormal synapse development in neurodevelopmental disorders.

\section{References}

Allen NJ, Eroglu C (2017) Cell biology of astrocyte-synapse interactions. Neuron 96:697-708. CrossRef Medline

Allen NJ, Bennett ML, Foo LC, Wang GX, Chakraborty C, Smith SJ, Barres BA (2012) Astrocyte glypicans 4 and 6 promote formation of excitatory synapses via GluA1 AMPA receptors. Nature 486:410-414. CrossRef Medline

Anagnostaras SG, Gale GD, Fanselow MS (2001) Hippocampus and contextual fear conditioning: recent controversies and advances. Hippocampus 11:8-17. CrossRef Medline

Araque A, Parpura V, Sanzgiri RP, Haydon PG (1999) Tripartite synapses: glia, the unacknowledged partner. Trends Neurosci 22:208-215. CrossRef Medline

Ballas N, Lioy DT, Grunseich C, Mandel G (2009) Non-cell autonomous influence of MeCP2-deficient glia on neuronal dendritic morphology. Nat Neurosci 12:311-317. CrossRef Medline

Barker AJ, Koch SM, Reed J, Barres BA, Ullian EM (2008) Developmental control of synaptic receptivity. J Neurosci 28:8150-8160. CrossRef Medline

Bong YS, Lee HS, Carim-Todd L, Mood K, Nishanian TG, Tessarollo L, Daar IO (2007) EphrinB1 signals from the cell surface to the nucleus by recruitment of STAT3. Proc Natl Acad Sci U S A 104:17305-17310. CrossRef Medline

Bush JO, Soriano P (2009) Ephrin-B1 regulates axon guidance by reverse signaling through a PDZ-dependent mechanism. Genes Dev 23:15861599. CrossRef Medline

Çaliskan G, Müller I, Semtner M, Winkelmann A, Raza AS, Hollnagel JO, Rösler A, Heinemann U, Stork O, Meier JC (2016) Identification of parvalbumin interneurons as cellular substrate of fear memory persistence. Cereb Cortex 26:2325-2340. CrossRef Medline

Carmona MA, Murai KK, Wang L, Roberts AJ, Pasquale EB (2009) Glial ephrin-A3 regulates hippocampal dendritic spine morphology and glutamate transport. Proc Natl Acad Sci U S A 106:12524-12529. CrossRef Medline

Chenaux G, Henkemeyer M (2011) Forward signaling by EphB1/EphB2 interacting with ephrin-B ligands at the optic chiasm is required to form the ipsilateral projection. Eur J Neurosci 34:1620-1633. CrossRef Medline

Christopherson KS, Ullian EM, Stokes CC, Mullowney CE, Hell JW, Agah A, Lawler J, Mosher DF, Bornstein P, Barres BA (2005) Thrombospondins are astrocyte-secreted proteins that promote CNS synaptogenesis. Cell 120:421-433. CrossRef Medline

Chung WS, Clarke LE, Wang GX, Stafford BK, Sher A, Chakraborty C, Joung J, Foo LC, Thompson A, Chen C, Smith SJ, Barres BA (2013) Astrocytes mediate synapse elimination through MEGF10 and MERTK pathways. Nature 504:394-400. CrossRef Medline

Clarke LE, Barres BA (2013) Emerging roles of astrocytes in neural circuit development. Nat Rev Neurosci 14:311-321. CrossRef Medline

Cowan CA, Henkemeyer M (2001) The SH2/SH3 adaptor Grb4 transduces B-ephrin reverse signals. Nature 413:174-179. CrossRef Medline

Cowan WM, Fawcett JW, O'Leary DD, Stanfield BB (1984) Regressive events in neurogenesis. Science 225:1258-1265. CrossRef Medline

Dalva MB, Takasu MA, Lin MZ, Shamah SM, Hu L, Gale NW, Greenberg ME (2000) EphB receptors interact with NMDA receptors and regulate excitatory synapse formation. Cell 103:945-956. CrossRef Medline

Donato F, Rompani SB, Caroni P (2013) Parvalbumin-expressing basketcell network plasticity induced by experience regulates adult learning. Nature 504:272-276. CrossRef Medline

Donato F, Chowdhury A, Lahr M, Caroni P (2015) Early-and late-born parvalbumin basket cell subpopulations exhibiting distinct regulation and roles in learning. Neuron 85:770-786. CrossRef Medline

Draft RW, Lichtman JW (2009) It's lonely at the top: winning climbing fibers ascend dendrites solo. Neuron 63:6-8. CrossRef Medline

Durand GM, Kovalchuk Y, Konnerth A (1996) Long-term potentiation and functional synapse induction in developing hippocampus. Nature 381: 71-75. CrossRef Medline

Eroglu C, Barres BA (2010) Regulation of synaptic connectivity by glia. Nature 468:223-231. CrossRef Medline

Eroglu C, Allen NJ, Susman MW, O'Rourke NA, Park CY, Özkan E, Chakraborty C, Mulinyawe SB, Annis DS, Huberman AD, Green EM, Lawler J, Dolmetsch R, Garcia KC, Smith SJ, Luo ZD, Rosenthal A, Mosher DF, Barres BA (2009) Gabapentin receptor $\alpha 2 \delta$-1 is a neuronal thrombospondin receptor responsible for excitatory CNS synaptogenesis. Cell 139:380-392. CrossRef Medline

Ethell IM, Irie F, Kalo MS, Couchman JR, Pasquale EB, Yamaguchi Y (2001) EphB/syndecan-2 signaling in dendritic spine morphogenesis. Neuron 31:1001-1013. CrossRef Medline

Filosa A, Paixão S, Honsek SD, Carmona MA, Becker L, Feddersen B, Gaitanos L, Rudhard Y, Schoepfer R, Klopstock T, Kullander K, Rose CR, Pasquale EB, Klein R (2009) Neuron-glia communication via EphA4/ ephrin-A3 modulates LTP through glial glutamate transport. Nat Neurosci 12:1285-1292. CrossRef Medline

Gaitanos TN, Koerner J, Klein R (2016) Tiam-rac signaling mediates transendocytosis of ephrin receptor EphB2 and is important for cell repulsion. J Cell Biol 215:431. CrossRef Medline

Garrett AM, Weiner JA (2009) Control of CNS synapse development by $\gamma$-protocadherin-mediated astrocyte-neuron contact. J Neurosci 29: 11723-11731. CrossRef Medline

Goshen I, Brodsky M, Prakash R, Wallace J, Gradinaru V, Ramakrishnan C, Deisseroth K (2011) Dynamics of retrieval strategies for remote memories. Cell 147:678-689. CrossRef Medline

Grunwald IC, Korte M, Adelmann G, Plueck A, Kullander K, Adams RH, Frotscher M, Bonhoeffer T, Klein R (2004) Hippocampal plasticity requires postsynaptic ephrinBs. Nat Neurosci 7:33-40. CrossRef Medline

Hama H, Hara C, Yamaguchi K, Miyawaki A (2004) PKC signaling mediates global enhancement of excitatory synaptogenesis in neurons triggered by local contact with astrocytes. Neuron 41:405-415. CrossRef Medline 
Harris EW, Ganong AH, Cotman CW (1984) Long-term potentiation in the hippocampus involves activation of $\mathrm{N}$-methyl-D-aspartate receptors. Brain Res 323:132-137. CrossRef Medline

Henderson JT, Georgiou J, Jia Z, Robertson J, Elowe S, Roder JC, Pawson T (2001) The receptor tyrosine kinase EphB2 regulates NMDA-dependent synaptic function. Neuron 32:1041-1056. CrossRef Medline

Henkemeyer M, Itkis OS, Ngo M, Hickmott PW, Ethell IM (2003) Multiple EphB receptor tyrosine kinases shape dendritic spines in the hippocampus. J Cell Biol 163:1313-1326. CrossRef Medline

Higashimori H, Schin CS, Chiang MS, Morel L, Shoneye TA, Nelson DL, Yang Y (2016) Selective deletion of astroglial FMRP dysregulates glutamate transporter GLT1 and contributes to fragile X syndrome phenotypes in vivo. J Neurosci 36:7079-7094. CrossRef Medline

Hollingsworth EB, McNeal ET, Burton JL, Williams RJ, Daly JW, Creveling CR (1985) Biochemical characterization of a filtered synaptoneurosome preparation from guinea pig cerebral cortex: cyclic adenosine $3^{\prime}: 5^{\prime}-$ monophosphate-generating systems, receptors, and enzymes. J Neurosci 5:2240-2253. CrossRef Medline

Holtmaat A, Svoboda K (2009) Experience-dependent structural synaptic plasticity in the mammalian brain. Nat Rev Neurosci 10:647-658. CrossRef Medline

Hussain NK, Thomas GM, Luo J, Huganir RL (2015) 0 regulation of AMPA receptor subunit GluA1 surface expression by PAK3 phosphorylation. Proc Natl Acad Sci U S A 112:E5883-E5890. CrossRef Medline

Isaac JT, Nicoll RA, Malenka RC (1995) Evidence for silent synapses: implications for the expression of LTP. Neuron 15:427-434. CrossRef Medline

Jacobs S, Nathwani M, Doering LC (2010) Fragile X astrocytes induce developmental delays in dendrite maturation and synaptic protein expression. BMC Neurosci 11:132. CrossRef Medline

Ji J, Maren S (2008) Differential roles for hippocampal areas CA1 and CA3 in the contextual encoding and retrieval of extinguished fear. Learn Mem 15:244-251. CrossRef Medline

Kalo MS, Yu HH, Pasquale EB (2001) In vivo tyrosine phosphorylation sites of activated ephrin-B1 and ephB2 from neural tissue. J Biol Chem 276: 38940-38948. CrossRef Medline

Kayser MS, McClelland AC, Hughes EG, Dalva MB (2006) Intracellular and trans-synaptic regulation of glutamatergic synaptogenesis by EphB receptors. J Neurosci 26:12152-12164. CrossRef Medline

Kucukdereli H, Allen NJ, Lee AT, Feng A, Ozlu MI, Conatser LM, Chakraborty C, Workman G, Weaver M, Sage EH, Barres BA, Eroglu C (2011) Control of excitatory CNS synaptogenesis by astrocyte-secreted proteins Hevin and SPARC. Proc Natl Acad Sci U S A 108:E440-E449. CrossRef Medline

Lauterbach J, Klein R (2006) Release of full-length EphB2 receptors from hippocampal neurons to cocultured glial cells. J Neurosci 26:1157511581. CrossRef Medline

Lichtman JW, Colman H (2000) Synapse elimination and indelible memory. Neuron 25:269-278. CrossRef Medline

Liebl DJ, Morris CJ, Henkemeyer M, Parada LF (2003) mRNA expression of ephrins and Eph receptor tyrosine kinases in the neonatal and adult mouse central nervous system. J Neurosci Res 71:7-22. CrossRef Medline

Lioy DT, Garg SK, Monaghan CE, Raber J, Foust KD, Kaspar BK, Hirrlinger PG, Kirchhoff F, Bissonnette JM, Ballas N, Mandel G (2011) A role for glia in the progression of Rett's syndrome. Nature 475:497-500. CrossRef Medline

Luo L, O'Leary DD (2005) Axon retraction and degeneration in development and disease. Annu Rev Neurosci 28:127-156. CrossRef Medline

Maletic-Savatic M, Malinow R, Svoboda K (1999) Rapid dendritic morphogenesis in CA1 hippocampal dendrites induced by synaptic activity. Science 283:1923-1927. CrossRef Medline

Matsuo N, Reijmers L, Mayford M (2008) Spine-type-specific recruitment of newly synthesized AMPA receptors with learning. Science 319:11041107. CrossRef Medline

Matsuzaki M, Honkura N, Ellis-Davies GC, Kasai H (2004) Structural basis of long-term potentiation in single dendritic spines. Nature 429:761-766. CrossRef Medline
Miles R, Tóth K, Gulyás AI, Hájos N, Freund TF (1996) Differences between somatic and dendritic inhibition in the hippocampus. Neuron 16:815823. CrossRef Medline

Milner B, Squire LR, Kandel ER (1998) Cognitive neuroscience and the study of memory. Neuron 20:445-468. CrossRef Medline

Murai KK, Nguyen LN, Irie F, Yamaguchi Y, Pasquale EB (2003) Control of hippocampal dendritic spine morphology through ephrin-A3/EphA4 signaling. Nat Neurosci 6:153-160. CrossRef Medline

Neves G, Cooke SF, Bliss TV (2008) Synaptic plasticity, memory and the hippocampus: a neural network approach to causality. Nat Rev Neurosci 9:65-75. CrossRef Medline

Nikolakopoulou AM, Koeppen J, Garcia M, Leish J, Obenaus A, Ethell IM (2016) Astrocytic ephrin-B1 regulates synapse remodeling following traumatic brain injury. ASN Neuro 8:1-18. CrossRef Medline

Nolt MJ, Lin Y, Hruska M, Murphy J, Sheffler-Colins SI, Kayser MS, Passer J, Bennett MV, Zukin RS, Dalva MB (2011) EphB controls NMDA receptor function and synaptic targeting in a subunit-specific manner. J Neurosci 31:5353-5364. CrossRef Medline

Oren I, Hájos N, Paulsen O (2010) Identification of the current generator underlying cholinergically induced gamma frequency field potential oscillations in the hippocampal CA3 region. J Physiol 588:785-797. CrossRef Medline

Paolicelli RC, Bolasco G, Pagani F, Maggi L, Scianni M, Panzanelli P, Giustetto M, Ferreira TA, Guiducci E, Dumas L, Ragozzino D, Gross CT (2011) Synaptic pruning by microglia is necessary for normal brain development. Science 333:1456-1458. CrossRef Medline

Schafer DP, Stevens B (2010) Synapse elimination during development and disease: immune molecules take centre stage. Biochem Soc Trans 38:476481. CrossRef Medline

Sloniowski S, Ethell IM (2012) Looking forward to EphB signaling in synapses. Semin Cell Dev Biol 23:75-82. CrossRef Medline

Spacek J, Harris KM (2004) Trans-endocytosis via spinules in adult rat hippocampus. J Neurosci 24:4233-4241. CrossRef Medline

Stevens CF, Williams JH (2007) Discharge of the readily releasable pool with action potentials at hippocampal synapses. J Neurophysiol 98:3221-3229. CrossRef Medline

Strekalova T, Zörner B, Zacher C, Sadovska G, Herdegen T, Gass P (2003) Memory retrieval after contextual fear conditioning induces $\mathrm{c}$-fos and JunB expression in CA1 hippocampus. Genes Brain Behav 2:3-10. CrossRef Medline

Takasu MA, Dalva MB, Zigmond RE, Greenberg ME (2002) Modulation of NMDA receptor-dependent calcium influx and gene expression through EphB receptors. Science 295:491-495. CrossRef Medline

Talebian A, Britton R, Ammanuel S, Bepari A, Sprouse F, Birnbaum SG, Szabó G, Tamamaki N, Gibson J, Henkemeyer M (2017) Autonomous and non-autonomous roles for ephrin-B in interneuron migration. Dev Biol 431:179-193. CrossRef Medline

Tsien JZ, Huerta PT, Tonegawa S (1996) The essential role of hippocampal CA1 NMDA receptor-dependent synaptic plasticity in spatial memory. Cell 87:1327-1338. CrossRef Medline

Tukker JJ, Fuentealba P, Hartwich K, Somogyi P, Klausberger T (2007) Cell type-specific tuning of hippocampal interneuron firing during gamma oscillations in vivo. J Neurosci 27:8184-8189. CrossRef Medline

Ullian EM, Sapperstein SK, Christopherson KS, Barres BA (2001) Control of synapse number by glia. Science 291:657-661. CrossRef Medline

Xu NJ, Henkemeyer M (2012) Ephrin reverse signaling in axon guidance and synaptogenesis. Semin Cell Dev Biol 23:58-64. CrossRef Medline

Yasumatsu N, Matsuzaki M, Miyazaki T, Noguchi J, Kasai H (2008) Principles of long-term dynamics of dendritic spines. J Neurosci 28:1359213608. CrossRef Medline

Ylinen A, Bragin A, Nádasdy Z, Jandó G, Szabó I, Sik A, Buzsáki G (1995) Sharp wave-associated high-frequency oscillation $(200 \mathrm{~Hz})$ in the intact hippocampus: network and intracellular mechanisms. J Neurosci 15:3046. CrossRef Medline 